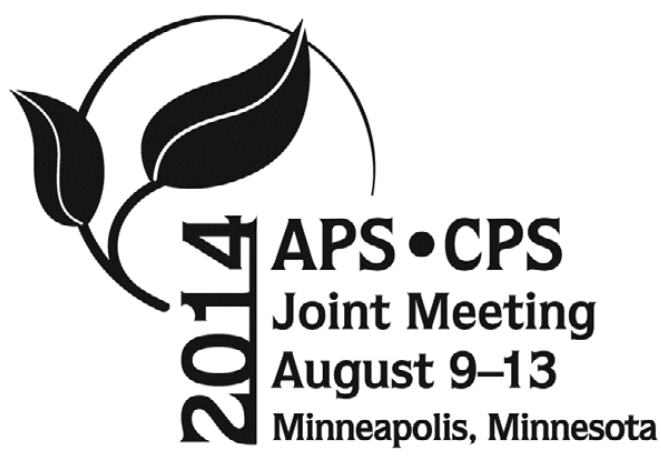

\title{
2014 APS-CPS Joint Meeting Abstracts of Special Session Presentations
}

\section{Biology of Pathogens}

\section{Frontiers in Biosynthesis and Management of Mycotoxins}

From one to many: Effective aflatoxin management in farmers' fields in West and East Africa

R. BANDYOPADHYAY (1), P. J. Cotty (2), J. Atehnkeng (1), S. E. Bonkoungou (3), K. A. Callicott (2), R. Jaime-Garcia (4), C. K. Mutegi (5), C. Probst (6), L. Senghor (7)

(1) International Institute of Tropical Agriculture (IITA), Ibadan, Nigeria; (2) USDA/ARS, School of Plant Sciences, University of Arizona, Tucson, AZ, U.S.A.; (3) INERA, Bobo-Dioulasso, Burkina faso; (4) University of Arizona, School of Plant Sciences, Tucson, AZ, U.S.A.; (5) International Institute of Tropical Agriculture (IITA), Nairobi, Kenya; (6) Washington State University, Prosser, WA, U.S.A.; (7) DPV, Dakar, Senegal

Phytopathology 104(Suppl. 3):S3.139

Aflatoxin (AF) contamination occurs throughout sub-Saharan Africa reducing trade opportunities and exposing populations to a potent carcinogen that causes liver cirrhosis, stunting, and reduced immune function. Use of atoxigenic strains of Aspergillus flavus to competitively exclude AF producers is an established tool for AF prevention in the US. Utilizing the same principles, highly effective biocontrol products were developed for several African nations. Each product uses 4 genetically distinct atoxigenic isolates of A. flavus as active ingredients. The isolates are endemic to target nations to ensure no introduction of exotics and adaptation to target agroecosystems. Adaptation to Africa began in Nigeria where the resulting product aflasafe ${ }^{\mathrm{TM}}$ was evaluated in farmer's fields for 5 seasons on over 500 fields. Treatments reduced $\mathrm{AF}$ by $82-95 \%$ in maize and peanut. Also in West Africa, products for Senegal (aflasafe SN01) and Burkina Faso (aflasafe BF01) were evaluated in farmer's fields for multiple seasons with reductions exceeding $75 \%$. Aflasafe KE01, developed for Kenya in East Africa, where lethal aflatoxicoses has been repeatedly reported had excellent efficacy on farm for two seasons. In one area, untreated controls averaged $>1,100 \mathrm{ppb}$ and treated fields $<75 \mathrm{ppb}$. The aflasafe biocontrol products have area-wide and long-term influences that offer real promise for relieving human populations in Africa of the health effects caused by chronic AF exposure.

The abstracts are published as submitted. They were formatted but not edited at the APS headquarters office.

http://dx.doi.org/10.1094/PHYTO-104-11-S3.139

(c) 2014 The American Phytopathological Society
Role of plant elicitor peptides and phytoalexins in enhancing maize resistance to Aspergillus flavus infection

A. HUFFAKER (1), J. Sims (1), S. Christensen (1), E. A. Schmelz (1)

(1) USDA-ARS CMAVE, Gainesville, FL, U.S.A.

Phytopathology 104(Suppl. 3):S3.139

Maize responds to pests and pathogens with complex defense responses. To facilitate effective breeding for pest and pathogen resistance, we're elucidating cellular and molecular functions of regulatory and metabolic components of these maize defense responses. Our studies of regulatory components have focused on a family of peptide signals (ZmPeps) and their cognate receptors (ZmPEPRs) that regulate maize immunity. One of these, ZmPep1, triggers synthesis of plant defense phytohormones and induces expression of genes encoding pathogenesis-related proteins. ZmPep1 also promotes accumulation of the maize defense chemical HDMBOA-Glc. Treatment of maize plants with ZmPep1 prior to inoculation enhances resistance to fungal pathogens. A second peptide, ZmPep3, induces plant resistance responses against Lepidopteran herbivores associated with spread of mycotoxin-producing fungal pathogens. ZmPep3 stimulates expression of proteinase inhibitor genes and emission of volatiles that attract natural enemies of herbivorous pests. We've also discovered two families of fungalinduced terpenoid phytoalexins that accumulate at the plant pathogen interface, the kauralexins and zealexins. Several of these terpenoids have antimicrobial activity and we're examining their effects on aflatoxin production. We aim to provide understanding of molecular processes regulating maize defense and new strategies for enhancing resistance to pests, disease and mycotoxin accumulation.

Genomic approaches to characterize the regulatory circuits of Aspergillus flavus controlling aflatoxin biosynthesis

G. PAYNE (1), X. Shu (1), G. OBrian (1), B. Musungu (2), M. Geisler (2), A. M. Fakhoury (2)

(1) North Carolina State University, Raleigh, NC, U.S.A.; (2) Southern Illinois University, Carbondale, IL, U.S.A.

Phytopathology 104(Suppl. 3):S3.139

Colonization of maize seeds with the opportunistic pathogen Aspergillus flavus leads to contamination with the carcinogen aflatoxin. To better understand this host-pathogen interaction and its impact on aflatoxin contamination, we monitored colonization by histology and gene expression by RNA-seq analysis at $12,24,48$, and $72 \mathrm{hr}$. Transcriptional changes in the three major defense-signaling pathways occurred early, followed by expression of defense-related genes. To gain additional insight into the dynamics of the host-pathogen interaction, 60 differentially expressed genes for hormones, defense, and metabolism were analyzed at $6 \mathrm{hr}$ intervals from 6 to $48 \mathrm{hr}$ and finally at $72 \mathrm{hr}$ by interrogating a recently built maize predicted 
protein-protein interactome, as well as static and dynamic gene expression networks. These networks were generated using gene expression data from $A$. flavus and maize. Some of the investigated maize genes acted as nodes in the maize predicted interactome revealing a central role in their interaction with other maize proteins. When the gene expression data from the $6 \mathrm{hr}$ intervals were superimposed on the interactome, the gene expression networks showed that several A. flavus genes directly interacted with these nodes in maize. This interaction indicates a high level of co-regulation between these maize and $A$. flavus genes revealing certain facets of interspecies cross-talk during colonization and aflatoxin contamination.

Insights into the evolution of mycotoxin biosynthesis in the fungus Fusarium

R. H. PROCTOR (1), T. Lee (2), M. T. Amatulli (3), S. P. McCormick (3), D. W. Brown (3), M. Busman (3), C. Maragos (3), T. J. Ward (3)

(1) USDA ARS MWA NCAUR, Peoria, IL, U.S.A.; (2) National Academy of Agricultural Science, Rural Development Administration, Suwon, Korea; (3) USDA ARS NCAUR, Peoria, IL, U.S.A.

Phytopathology 104(Suppl. 3):S3.140

Collectively species of Fusarium are pathogens of almost all economically important plants and produce over 50 families of secondary metabolites (SMs), including some of the mycotoxins (e.g. fumonisins and trichothecenes) of greatest concern to food/feed safety. In fungi, genes responsible for biosynthesis of an SM are usually located next to one another in a gene cluster. A typical biosynthetic gene cluster encodes enzymes that catalyze SM synthesis, a transport protein for SM secretion, and a regulatory protein that controls transcription of cluster genes. Comparative analyses of such clusters have provided insight into evolutionary processes responsible for variation in mycotoxin production in Fusarium. Presence and absence of a cluster is the primary cause of interspecies differences in ability versus inability to produce a mycotoxin. In some cases, this variation in ability has resulted from relatively recent horizontal transfer or loss of a cluster. In addition, intra- and inter-species differences in production of different analogues of a mycotoxin family can result from loss of a cluster gene or from variation in function of homologs of a gene. In contrast, some clusters exhibit marked variation in DNA sequences or gene organization without effects on mycotoxin production. Thus, SM gene clusters can be dynamic genetic elements, and this dynamism is responsible for qualitative differences in mycotoxin production within and among species of Fusarium.

Genetics and next-generation sequencing in identifying marker for aflatoxin resistance in maize

M. L. WARBURTON (1), W. P. Williams (1), G. Windham (1), S. Murray (2), W. Xu (2), A. Perkins (3), J. Tang (1), L. Hawkins (1)

(1) USDA ARS CHPRRU, Mississippi State, MS, U.S.A.; (2) Dept. Soil and Crop Sciences TAMU, College Station, TX, U.S.A.; (3) Computer Science and Engineering Mississippi State University, Mississippi State, MS, U.S.A. Phytopathology 104(Suppl. 3):S3.140

Resistance to aflatoxin accumulation and ear rot caused by Aspergillus flavus has been studied using various genetic mapping strategies. Quantitative Trait Loci mapping has identified several QTL for resistance from various sources, but little is known about underlying genes and mechanisms. An association panel of 300 maize inbred lines was genotyped by sequencing and phenotyped as testcrosses for aflatoxin levels following inoculation by A. flavus in replicated trials in 8 environments. Over $400 \mathrm{~K}$ Single Nucleotide Polymorphisms were identified. After filtering for minor allele frequency $>5 \%, 261,184$ SNPs were used for genome wide association study, in which we identified 117 SNPs associated with aflatoxin levels in grain $(P \leq 9.78 \times$ $\left.10^{-6} \mid 1 / \mathrm{N}\right)$. Ten SNP/trait associations exceeded the $10 \%$ false discovery rate level $\left(\mathrm{p}<3.83 \times 10^{-7}\right)$. These 10 significant associations fall within linkage disequilibrium distance of 5 genes. The work of characterizing the correct candidate genes will now begin. Multiple associations (between one or multiple linked SNPs and aflatoxin levels in one or more environments) increase confidence of certain regions; 21 of these regions with multiple associations were identified. Thirteen of 10 associated SNPs or 21 regions fell within a previously identified QTL. The associated SNPs and their gene effects are being analyzed with annotated maize pathways to help identify genetic resistance mechanisms.

\section{Innovative Approaches to Control Difficult Bacterial Pathogens} Virulent bacteriophages of Xylella fastidiosa: Potential biocontrol agents
for Pierce's Disease

M. Das (1), T. S. Bhowmick (1), S. J. Ahern (1), R. F. Young (2), C. F. GONZALEZ (1)

(1) Department of Plant Pathology and Microbiology, Texas A\&M University, College Station, TX, U.S.A.; (2) Department of Biochemistry and Biophysics, Texas A\&M University, College Station, TX, U.S.A.

Phytopathology 104(Suppl. 3):S3.140

Xylella fastidiosa is the causal agent of Pierce's Disease (PD), a major threat to the wine industry in the USA. Currently, there are no effective control measures to prevent infection or manage the disease, short of aggressive culling of infected vines, once established in a vineyard. The search for new methods to combat microbial pathogens is an ongoing process in both medicine and agriculture. Bacteriophages (phages; bacterial viruses) offer a novel strategy not previously pursued for the control of PD, because methods to isolate and propagate viable virulent phages were not available. Bacteriophages specifically target the underlying bacterial pathogen, without posing any harmful effects to humans, animals or plants. Our laboratory has isolated and characterized virulent phages for $X$. fastidios $a$, making feasible the development of phage therapy for the treatment of PD. The therapeutic and preventative efficacy of a phage cocktail composed of virulent phages Sano, Salvo, Prado and Paz to protect grapevines (Vitis vinifera cv. Cabernet Sauvignon) against $X$. fastidios $a$ was evaluated in greenhouse experiments. The results demonstrated the efficacy of phages in both treatments. An ongoing trial will test efficacy under field conditions. Application of phages as a biocontrol agent for $X$. fastidiosa offers a novel biological treatment for control of PD.

Changing an enemy into an ally to manage citrus diseases

W. O. DAWSON (1)

(1) University of Florida, Department of Plant Pathology, Citrus Research and

Education Center, Lake Alfred, FL, U.S.A.

Phytopathology 104(Suppl. 3):S3.140
We created a transient-expression vector based on Citrus tristeza virus (CTV) to express foreign genes or silence endogenous genes in citrus. This vector can be graft transmitted and expressed in a range of citrus varieties of different ages. The original objective was to build a vector as a tool for citrus improvement. With the emergence of the citrus greening disease into Florida, we began screening genes for activity against the bacterial pathogen or the psyllid vector, with the intention of building transgenic citrus with the genes found to be effective. However, the spread of greening in Florida has been more rapid than expected and there is desperate need to find solutions quicker than transgenic trees. The CTV vector is now being considered for use in the field as an interim measure until transgenic citrus becomes available. Additionally, if we can find appropriate genes, it is possible that the CTV vector can be used to treat trees in the field after they become infected with citrus greening. A disadvantage of the vector is that it does not permanently retain foreign sequences, but a major advantage of the vector is that nothing is put into the environment permanently.

\section{Candidatus Liberibacter associated diseases: Challenges and opportunities} H. LIN (1)

(1) USDA ARS, Parlier, CA, U.S.A.

Phytopathology 104(Suppl. 3):S3.140

Pathogenic "Candidatus Liberibacter" species have caused tremendous economic losses to agricultural crops. Since the causative agents are yet unculturable, information regarding genetics and pathogenesis of the pathogens is limited. Comparative analyses of multiple Liberibacter genomes provide unprecedented insights into the evolutionary history, phylogenetic diversity and metabolomic capacities in these pathogenic bacteria. The available of genomic information also led to identification of potential or putative pathogenicity and virulence factors, biomarkers associated with Liberibacterhost plant interactions as well as development of improved, reliable diagnostic protocols for early (i.e. pre-symptomatic), rapid Liberibacter detection. Since no host resistance has been found in Liberibacter-associated diseases, knowledge of specific Liberibacter genes and their products associated with pathogenicity and virulence, as well as interactions with hosts is extremely important in understanding pathogenesis. In spite of uncultivable nature of Liberibacter, a novel technique for functional determinant of virulence genes 
had been developed. This technique facilitates identification of potential targets for mitigating Liberibacter acquisition and transmission by psyllids, host plant infection and disease development. Finally, genomics-based research will improve our understanding of the complex and diverse mechanisms of Liberibacter - plant interactions.

Factors influencing transmission of the huanglongbing pathogen by the Asian citrus psyllid and methods for interrupting the transmission process

K. PELZ-STELINSKI (1)

(1) University of Florida, Lake Alfred, FL, U.S.A.

Phytopathology 104(Suppl. 3):S3.141

The Asian Citrus Psyllid, Diaphorina citri (Hemiptera: Liviidae), a phloem feeding citrus pest, transmits Candidatus Liberibacter asiaticus (Las), the causal agent of citrus Huanglongbing (HLB) disease found in Florida and increasingly throughout all citrus growing areas of the United States. Understanding the biological and environmental factors, including age, temperature exposure, and host preference, that influence the vector capacity of $D$. citri is critical for the development of effective pest and disease management strategies. Currently, microbial-mediated disruption of Las transmission is one such strategy under investigation. Our findings suggest that Las transmission is influenced by the native microbial community present in $D$. citri, and these communities differ among populations of $D$. citri. In particular, infections with the endosymbiont Wolbachia vary significantly among $D$. citri, which may indicate spatial differences in host-endosymbiont interactions between D. citri and Wolbachia. Here, we discuss manipulations of Wolbachia strains within $D$. citri as a novel tool for disruption of Las transmission.

Precise engineering of plant genomes with sequence-specific nucleases D. F. VOYTAS (1)

(1) University of Minnesota, St. Paul, MN, U.S.A.

Phytopathology 104(Suppl. 3):S3.141

Methods for precisely altering DNA sequences in living cells enable detailed functional analysis of genes and genetic pathways. In plants, targeted genome modification has applications ranging from understanding plant gene function to developing crop plants with new traits of value. Our group has enabled efficient methods for targeted genome modification of plants using sequencespecific nucleases. With zinc finger nucleases (ZFNs), TAL effector nucleases (TALENs), and the CRISPR/Cas9 system, we have achieved targeted gene knockouts, replacements and insertions in a variety of plant species. Current work is focused on optimizing delivery of nucleases and donor DNA molecules to plant cells to more efficiently achieve targeted genetic alterations.

\section{Schroth Faces of the Future: Virology}

Visualizing molecular signatures of host-virus protein interactions using high resolution mass spectrometry

M. L. CILIA (1), J. E. Bruce (2), S. L. DeBlasio (1), J. D. Chavez (2), J. Mahoney (3), J. Eng (4), S. M. Gray (1)

(1) USDA Agricultural Research Service, Ithaca, NY, U.S.A.; (2) University of Washington, Seattle, WA, U.S.A.; (3) Boyce Thompson Institute for Plant Reasearch, Ithaca, NY, U.S.A.; (4) University of Washington Proteomics Resource, Seattle, WA, U.S.A.

Phytopathology 104(Suppl. 3):S3.141

Host-pathogen protein interactions are largely uncharted due to technical challenges inherent in studying the host-virus interface at the biochemical level. The majority of interactions are not binary or easily amenable to structural determination. Using infectious preparations of a polerovirus (Potato leafroll virus, PLRV) and Protein Interaction Reporter, a novel technology that couples a mass spectrometric-cleavable chemical cross-linker with high resolution mass spectrometry, we provide the first report of any host-pathogen protein interaction network that includes data-derived, topological features for every cross-linked site that was identified. We show that PLRV virions have hot spots of protein interaction and multifunctional surface topologies, revealing how these viruses maximize their use of protein interaction interfaces. Modeling data, guided by cross-linking constraints, suggest asymmetric packing of the capsid protein in the virion in line with previous epitope mapping studies. Protein interaction topologies are conserved with other species in the Luteoviridae and with unrelated viruses in the Herpesviridae and Adenoviridae, suggestive of convergent evolution of virus-host interactions across broad taxa of viruses and their hosts. Structural mimicry and diversifying selection were identified within interacting host and viral protein topologies - hallmark molecular signatures of host-pathogen interactions.

Identification of new and previously unreported plant viruses from North America and Ecuador: The first step towards virus disease management D. F. QUITO-AVILA (1)

(1) Centro de Investigaciones Biotecnologicas del Ecuador CIBE-ESPOL, Guayaquil, Ecuador

Phytopathology 104(Suppl. 3):S3.141

New and previously unreported viruses associated with emerging diseases have been found in several economically important crops in the USA and Ecuador during the past three years. In blueberry, a new virus (Blueberry necrotic ring blotch virus) was identified from plants showing irregularly shaped circular spots or blotches with green centers on leaves. The virus contains an RNA genome of $\sim 14 \mathrm{~kb}$ divided into four segments and has been found in several south-eastern states in the USA. In Ecuador, extensive surveys were carried out to obtain baseline information on the presence and commonality of viruses affecting important crops. Raspberry bushy dwarf virus was found and reported for the first time in the Andean blackberry Rubus glaucus, grown commercially in Ecuador. Interestingly, sequencing analysis showed an unusual genomic feature in RNA 2 of the Ecuadorian isolate. In cucurbits, Melon yellow spot virus (MYSV), a thrips-borne Tospovirus, and the partially described Melon Endornavirus (MelEV) were found and reported for the first time in the country. Specific primers designed to detect each virus showed that MYSV was present in $40 \%, 64 \%$ and $67 \%$ of the watermelon, cucumber and melon samples, respectively. For MelEV, 95\% of melon plants tested positive for the virus. In papaya, sequencing of dsRNA from symptomatic leaves revealed the presence of a novel virus with $38 \%$ amino acid (aa) identity to Carrot mottle virus, a $4.2 \mathrm{~kb}$ Umbravirus found naturally in carrot.

Reverse genetics and virus epidemiology: Integrating basic and applied research for disease management

T. THEKKE-VEETIL (1)

(1) Department of Plant Pathology, Division of Agriculture, University of Arkansas System, Fayetteville, AR, U.S.A.

Phytopathology 104(Suppl. 3):S3.141

Diseases caused by plant viruses result in substantial economic damage worldwide and pose serious threats to food security. Increases in international trade and the effect of climate change on virus epidemiology have impacted the dynamics of disease occurrence and resulted in emergence of viral diseases. These developments call for comprehensive science-based approaches for effective control and management of viral diseases. Genomic techniques like next-generation sequencing and advanced molecular detection tools have significantly improved the identification of new viruses and certification programs. Development of virus resistant or vector resistant plants through approaches that disrupt viral, plant or vector components essential for disease cycle also offers a promising future. Reverse genetics is a powerful approach to study the intricacies of plant-viral-vector interactions at molecular level. My research work aligns with the goal of disease prevention and management by focusing on both epidemiology and molecular biology of new and known viruses. Development of reverse genetic systems and analyses of important check-points in a virus life cycle and identification and molecular characterization of new viruses infecting crops, including their population structure and epidemiology will be discussed. Information gathered could be used in management practices to prevent the spread of these viruses. 


\section{Disease Control and Pest Management}

\section{A Systems Approach for Microbe Management: From Food Safety to Plant Health}

Introduction: Why do we need systems approaches to manage plant diseases?

N. J. GRUNWALD (1)

(1) Oregon State University, Department of Botany and Plant Pathology, US Department of Agriculture-Agricultural Research Service, Horticultural Crop Research Unit, Corvallis, OR, U.S.A.

Phytopathology 104(Suppl. 3):S3.142

Crop and food production systems are complex operations that have to balance and optimize various agronomic and economic factors that are often working against each other including pests and pathogens. Systems approaches were pioneered in the food industry and are now gaining acceptance in crop production systems. A systems approach is used to minimize the risk of food- or crop-associated pests and pathogens. A systems approach consists of a Hazard Analysis of Critical Control Points (HACCP) to identify, evaluate and correct sources of hazards such as pest and/or pathogens. Several flavors of systems approaches have been implemented in the food industry and more recently in crop production systems. This symposium will explore the implementation, use, and benefits of using systems approaches for managing microbes and pathogens in food and plant production systems.

Bacterial rots of sweet onion in Pennsylvania: Tracking sources of infection and targeting critical management points

B. K. GUGINO (1), M. A. Mansfield (1), E. E. Pfeufer (1)

(1) The Pennsylvania State University, University Park, PA, U.S.A.

Phytopathology 104(Suppl. 3):S3.142

Pennsylvania sweet onion growers are challenged by bacterial diseases which may result in up to $50 \%$ in-field and post-harvest yield losses. A multidisciplinary systems approach was utilized to address the observed between-field variability in yield losses and develop targeted management strategies based on potential sources of inoculum and production factors related to disease incidence. In 2011 and 2012, replicated survey plots were established and followed through the season on 28 and 26 commercial farms. Primary results indicated a positive relationship between soil temperature at the $4 \mathrm{~cm}$ depth and bacterial disease incidence. This supports replicated trial results which found that alternative plastic mulches reduced soil temperatures and resulted in lower disease incidence compared to standard black mulch. In addition, an unexpected negative relationship between foliar tissue nitrogen (N) and disease incidence was observed. While tissue $\mathrm{N}$ data was intended to update fertigation recommendations, these observations have led to replicated trials investigating the timing of $\mathrm{N}$ application and its relationship to disease and marketable yield. Pathogenicity testing of recovered bacterial isolates and DNA fingerprinting using rep-PCR have also linked transplants and weeds as potential sources of inoculum. More broadly, these results support an integrated, season-long approach to disease management to reduce potential losses from bacterial diseases.

\section{The Hazard Analysis Critical Control Point (HACCP) approach}

S. ILIC (1)

(1) The Ohio State University, Columbus, OH, U.S.A.

Phytopathology 104(Suppl. 3):S3.142

HACCP (Hazard Analysis Critical Control Point) is a preventive systematic approach to food safety. HACCP addresses biological, chemical and physical contamination of a product within its production chain. Other food safety and quality management systems (ISO22000, GFSI, SQF) incorporate HAPPC into their standards. HACCP involves identifying hazards and controlling them through prerequisite programs (PRPs) and/or Critical Control Points (CCPs). Food safety systems microbial contamination and cross-contamination is controlled and managed mostly by PRPs which ensure that environment is adequate for safe food production (Sanitation Program, Personal Hygiene, etc). After a safe processing environment is achieved, seven HACCP principles are implemented. Hazard analysis is the first principle, in which microbial and other hazards are identified and assessed. Following are identification of CCPs, establishment of limits, monitoring, corrective actions, record keeping and verification. For on-farm operations and packing facilities where there is a lack of kill step for microbial hazards, the use of HACCP principles alongside strong GAPs reduces the likelihood of contamination and enhance food safety. Prevention is a cornerstone of FDA's FSMA. FDA mandates HACCP-based preventive controls across the food supply to all facilities that in any way process fresh produce. The HACCP approach offers a practical and important contribution to the improved food supply in the US.

A systems approach for producing greenhouse tomatoes free of human pathogens and plant pathogens

M. LEWIS IVEY (1), S. Ilic (2), F. Baysal-Gurel (3), J. T. LeJeune (3), S. A. Miller (3)

(1) Agcenter, Louisiana State University, Baton Rouge, LA, U.S.A.; (2) The Ohio State University, Columbus, OH, U.S.A.; (3) The Ohio State University, Wooster, OH, U.S.A.

Phytopathology 104(Suppl. 3):S3.142

There is renewed interest in tomato greenhouse production in the US due to increased demand for year-round locally produced tomatoes. Risk factors such as plant diseases, insects and water quality are inherent to greenhouse tomato production sustainability and profitability. The risk of human pathogen contamination in the production system is not well understood. Many production practices are potential risk factors for the introduction and dissemination of pathogens through the system. A systems approach was implemented to identify and confirm critical points for pathogen entry and dissemination, and economical preventative strategies to mitigate risk. A production flow diagram was developed based on 26 site evaluations of small, medium and large greenhouses. In terms of economic consequences, industry ranked bacterial canker and Botrytis grey mold as major plant disease hazards. The Delphi Process was used to elicit the opinions of 46 plant pathologists and food safety experts to confirm practices that are critical points for pathogen entry and dissemination. Irrigation water, crop debris, production equipment, and workers were identified as common risk factors for both plant and human pathogens. Eight greenhouses were sampled over time to determine the relevance of each of the identified sources within the production system. Critical entry/dissemination points were identified for Botrytis grey mold, bacterial canker and Listeria monocytogenes.

A systems approach for managing Phytophthora diseases in horticultural nurseries

J. L. PARKE (1)

(1) Oregon State University, Corvallis, OR, U.S.A.

Phytopathology 104(Suppl. 3):S3.142

A systems approach was applied to four horticultural nurseries in Oregon to inform Phytophthora disease management. First, a hazard analysis was conducted to determine sources of Phytophthora contamination in the nursery production cycle. Plants, potting media, used containers, water, greenhouse soil, and container yard substrates were systematically sampled from the propagation phase to the field production phase. Overall, a total of 674 Phytophthora isolates representing 28 different species or taxa were identified. Each taxon was then categorized according to ecological guild to better assess disease risk. Approximately $29 \%$ of the Phytophthora isolates were recovered from untreated water reservoirs but most of the waterborne taxa were considered aquatic opportunists rather than plant pathogens. However, three novel taxa with unknown pathogenicity, including two hybrids, were detected from untreated water. Only $1 \%$ of the isolates were recovered from potting media, $2 \%$ from used containers, and $0.6 \%$ from treated irrigation water. More than $16 \%$ of the isolates were recovered from soil and gravel substrates in greenhouses, container yards, and in-ground field production sites, and many of these soil isolates belonged to plant pathogenic taxa that were also recovered from plants (51\% of isolates). These findings identify contamination hazards and target critical control points for management of Phytophthora diseases in horticultural nurseries.

Critical role of practical research and extension in a systems approach to microbial food safety for the produce supply-chain

T. V. SUSLOW (1)

(1) University of California, Davis, CA, U.S.A.

Phytopathology 104(Suppl. 3):S3.142

Since the dissemination of the first produce industry-guidance using the term Good Agricultural Practices (GAPs; 1996), the basic tenants of a systems approach to microbial food safety have remained constant. The corerecognized risks include; water - workers - soil amendments - domestic animals and wildlife - equipment and facility sanitation. Since then, detailed characterization of these and related hazards have been elucidated by basic 
and applied research. However, knowledge gaps in risk assessment and the specific efficacy of presumptive preventive controls, across diverse agroecoregions, commodities, and practices, remain barriers to effective design of best practice guidance and standards. Applied research and extension training have played a critical role for over 18 years in defining the voluntary producer or buyer-mandated GAPs requirements, preharvest to postharvest, which span all facets of the fresh produce supply-chain. Model and field-based research collectively demonstrate frequent interconnectivity of hazards along the supply-chain. In doing so, the necessity of taking a systems approach to minimizing risks and establishing multiple hurdles to illness or outbreaks has been well established. This presentation will provide case examples of realworld challenges preventing contamination and the downstream consequences of system failures that form the informational foundation for lessons learned that help guide our evolving risk management awareness.

\section{Banned: Turfgrass Disease Control in the Age of Restrictive Pesticide Legislation}

Fate and risk of pesticides applied to turfgrass systems

M. CARROLL (1)

(1) University of Maryland, Columbia, MD, U.S.A.

Phytopathology 104(Suppl. 3):S3.143

Public concern about pesticide usage most often centers on unwanted exposures that could affect mammalian health and the preservation of terrestrial and aquatic ecological resources. The fate of a pesticide is driven by the interaction of mobility and persistence factors present in the environment as well as the chemical properties of the pesticide itself. In plant-based systems, pesticide movement is also depended on the way in which the system is managed. Perennial plant communities, such as turfgrass, can dramatically reduce the persistence and mobility of many pesticides when paired with the use of management practices that enhance the retention of pesticides within the organically rich zone that exist near the soil surface in these plant communities. The ongoing development and registration of reduced risk pesticides, together with more stringent restrictions placed on the use of reregistered pesticides has reduced the ecological risks associated with the use of these pesticides. Similarly, the inclusion of multiple avenues of exposure in the assessment of human risks associated with pesticide use, mandated by the 1996 Food Quality Protection Act, has resulted in the loss of some pesticides for use on turfgrass.

The Vineyard Club: A case study of pesticide-free turfgrass management J. INGUAGIATO (1), J. Carlson (2)

(1) University of Connecticut, Storrs, CT, U.S.A.; (2) Vineyard Golf Club, Edgartown, MA, U.S.A.

Phytopathology 104(Suppl. 3):S3.143

Organic turfgrass management is not commonly practiced on golf courses where diseases can damage turf surfaces and disrupt play. The Vineyard Golf Club was mandated by the local permitting agencies on the Island of Martha's Vineyard, MA to be organically managed. They defined organic as being managed without the benefit of synthetically derived pesticides. When The Vineyard Golf Club (VGC) opened for play in May of 2002, Dollar Spot (caused by Sclerotinia homoeocarpa F.T. Bennett) was the most common disease of fairway and putting green turf on the course. Management of this disease focuses on the use of plant defense inducing products (i.e., Civitas), frequent applications of biological control products (e.g., Ecoguard and Rhapsody) and fertility to encourage rapid recovery of disease symptoms. Success of organic practices is also achieved through communications with the members. VGC members take pride in the organic management program and tolerate temporary reductions in turf quality on certain areas of the course. This presentation will highlight the organic management program as it has evolved through the last 12 years.

Public perception of pesticide use and current regulatory debates in the United States

C. MCKEEL (1)

(1) Golf Course Superintendents Association of America, Lawrence, KS, U.S.A. Phytopathology 104(Suppl. 3):S3.143

\section{EPA's Endocrine Disruptor Screening Program and Its Relationship to Plant Protection Products}

The Endocrine Disruptor Screening Program and a potential relationship to future plant disease control efforts

P. M. BRANNEN (1), L. A. Fall (2)

(1) University of Georgia, Athens, GA, U.S.A.; (2) University of Georgia, Byron, GA, U.S.A.

Phytopathology 104(Suppl. 3):S3.143
Golf courses rely upon the judicious use of inputs including pesticides to produce healthy turfgrass. Integrated pest management is key to healthy turfgrass and is part of the agronomic and environmental BMPs. Healthy turf provides benefits including crucial "greenspaces", habitat for birds and wildlife, recreational opportunities, and municipal revenue generated by outdoor recreational facilities. Cities and counties across the U.S. are debating ordinances to ban/restrict the use of chemical pesticides on city/public property. Local bans/restrictions on pesticide use is a trend that has gained momentum since the city of San Francisco, Calif., adopted such an ordinance in 1996. Many states have preemption (or "state primacy") laws to prohibit municipalities from adopting local laws and regulations on the use of pesticides and fertilizers. Without such laws, more than 80,000 municipalities in the U.S. could adopt and enforce their own unique ordinances, including use and applicator certification, making compliance difficult. Local pesticide restrictions hinder the ability of golf course superintendents to control pests that have a detrimental effect on healthy turf. Golf course management is not well known and misperceptions persist about the golf industry. Regulatory scrutiny over input use is on the rise and the golf industry must have a seat at the policymaking table to address these challenges.

\section{Alternatives ways for managing turfgrass diseases}

\section{J. M. VARGAS (1)}

(1) Michigan State University, East Lansing, MI, U.S.A.

Phytopathology 104(Suppl. 3):S3.143

Biological control with microorganisms is one alternative to managing turfgrass diseases without fungicides. However, most attempts to control with microorganisms have failed. It appears it's difficult to establish introduced microorganisms and have them become established in the field which is understandable considering all the naturally occurring organisms that have established themselves already in their own microclimate. Plant activators offer some promise, but only time will tell if they will be effective. Resistant cultivars whether developed through classical plant breeding or genetic engineering may offer the best hope of reducing fungicide usage in controlling turfgrass diseases. Examples of successful use of cultural, biological, and genetics include melting out and necrotic ring spot in Kentucky bluegrass as well as new findings for dollar spot control in creeping bentgrass. For this to work on dollar spot effective means of controlling Poа аппиа will have to be developed.

\section{Canadian pesticide restrictions - A cautionary history}

T. YAMADA (1)

(1) IPM Council of Canada, Milton, ON, Canada

Phytopathology 104(Suppl. 3):S3.143

The 2001 Canadian Supreme Court ruling that supported a municipality's right to restrict pesticides sparked a nationwide struggle over who determines access to these products. Federal regulators have traditionally based their decisions on science, but more local authorities may not have the financial or scientific resources to cope with this issue. The use of pesticides for turfgrass and ornamentals became a lightning rod, as these were deemed non-essential or cosmetic uses. However, the agricultural sector remains concerned that this is just the thin edge of the wedge for anti-pesticide advocates. The public's continued suspicion of all things chemical continues to pressure all levels of government, but may also provide some opportunities in plant health care research focused on lower risk products and management techniques.

The Environmental Protection Agency (EPA) is currently overseeing the Endocrine Disruptor Screening Program (EDSP), and at least 15 commonly utilized fungicides are on the Tier 1 screening list. Those that are found to impact any aspect of the endocrine system will be advanced to Tier 2 screening, which may result in further limitations of use or even cancellations of registrations. The Tier 1 list includes fungicides such as captan, chlorothalonil, flutolanil, fosetyl-Al, iprodione, metalaxyl, myclobutanil, propiconazole, tebuconazole, thiophanate-methyl, triadimefon, triflumizole, triphenyltin hydroxide, vinclozolin, and ziram; these compounds are respresentative of several FRAC chemical groups to include acylalanines (4), 
chloronitriles (M5), dicarboximides (2), dithiocarbamates (M3), ethyl phosphonates (33), phthalimides (M4), phenyl-benzamides (7), thiophanates (1), triazoles (3), and triphenyltins (30). Tier 2 screening can be predicted for several because of documented associations with endocrine disruption. Many of these fungicides are integral components in resistance-management programs due to low or moderate risk of resistance development in target fungi. Cancellation or additional use limits for these fungicides will increase resistance pressure for the remaining fungicide classes and may therefore pose negative long-term implications for disease management; in addition, secondary pathogens may emerge, as many of these are broad-spectrum fungicides.

EPA's Endocrine Disruptor Screening Program: Background and evaluation of Tier 1 results from chemical case studies

P. BROWNE (1)

(1) US EPA - Office of Science Coordination and Policy, Washington, DC, U.S.A.

Phytopathology 104(Suppl. 3):S3.144

The US Environmental Protection Agency's Endocrine Disruptor Screening Program was established as two-tiered approach to determine if a chemical poses a risk to human or environmental health through interactions with the estrogen, androgen, and thyroid hormone signaling pathways. Based on recommendations of the 1998 Endocrine Disruptor Screening and Testing Advisory Committee, EPA developed an 11 assay Tier 1 screening battery and definitive Tier 2 tests to characterize potential adverse effects of chemical exposures and dose-response relationships. In some instances, other scientifically relevant information may be substituted for EDSP assays. The need for Tier 2 or other additional testing to inform the risk assessment process will be made from a weight-of-evidence determination of Tier 1 results and take into account other scientifically relevant information available from peer-reviewed literature or other sources. EPA's weight-of-evidence process follows a hypothesis-driven approach using an adverse outcome pathway conceptual framework to integrate complex data along a biological continuum of key events from molecular initiating events to in vivo outcomes. The method for interpreting endpoints from the 11 Tier 1 screening assays along with other available information will be discussed in the context of two chemical case studies. The Agency's approach and chemical case studies were presented to and endorsed by a July 2013 FIFRA Scientific Advisory Panel review.

\section{Industry perspective}

B. CARROLL (1)

(1) Greensboro, NC, U.S.A.

Phytopathology 104(Suppl. 3):S3.144

In 1996 provisions were added to the Food Quality Protection Act and the Safe Drinking Water Act to require chemical screening for potential endocrine effects. The framework developed to accomplish these requirements is called the Endocrine Disruptor Screening Program (EDSP). Pesticide registrants are required to conduct studies of a higher tier than the EDSP Tier I battery under the Federal Insecticide, Fungicide and Rodenticide Act for the purpose of identifying potential reproductive effects. Validation of all studies employed in the EDSP is imperative so the results are reliable, and further there must be consistent application of objective criteria for the EDSP Tier I battery, including the use of scientifically appropriate interpretation of these data in order to meet requirements of the Information Quality Act. The Environmental Protection Agency (EPA) should be explicit in its indication of the limitations on the interpretation of EDSP Tier I test results. Data suggesting endocrine-related activity must be viewed in the appropriate context, e.g. is it transient or reversible and therefore not necessarily adverse.
It should not be interpreted on its own as evidence of adverse effects. When conducting safety assessments the EPA should use "weight-of-the-evidence" methodology to consider all relevant information as opposed to reliance on unique and non-repeatable data. While there have been efforts by the US and other countries over the past two decades from the standpoint of assessment of chemical safety, no comparable attempts to harmonize and mutually accept testing strategies and decision-making criteria for chemicals undergoing EDSP screening has occurred. Considering the unique requirements and endpoints necessary to assess endocrine potential, development of standardized programs based on scientifically valid data and appropriate endpoints will take additional time and effort for advancement of uniform safety evaluation procedures.

\section{The legislative history of the Endocrine Disruptor Screening Program} K. EVERSOLE (1)

(1) Eversole Associates, Bethesda, MD, U.S.A.

Phytopathology 104(Suppl. 3):S3.144

Endocrine disruptors are naturally occurring or man-made substances/ compounds that mimic or interfere with the endocrine system of animals. While the phrase "endocrine disruptor" was not coined until the early 1990s, scientific evidence confirmed by the middle of the 20th century that both natural and synthetic chemicals could interact with endogenous hormone receptors. In response to several scientific and popular-press articles published in the early 1990s, the US Congress mandated the screening of pesticide chemicals and drinking water contaminants for potential disruptions to endocrine systems. In its 1996 amendments to Federal pesticide legislation, Congress enacted the Food Quality Protection Act (FQPA; Public Law 104170) and directed the Environmental Protection Agency (EPA) to require validated tests to determine the potential of pesticides to produce effects in humans similar to those produced by naturally occurring estrogens. In addition, at the discretion of the EPA administrator, FQPA authorized the EPA to consider the cumulative effect of pesticides to which a substantial proportion of the population may be exposed. In the same year, Congress passed the Safe Drinking Water Act Amendments (Public Law 104-182) that authorized screening for endocrine disrupting contaminants in drinking water. This presentation will provide an overview of the legislative history of the resulting Endocrine Disruptor Screening Program.

Endocrine disruptor screening: Considerations for compound design and selection of new disease control products

C. A. S. PEARSON (1), D. Wolf (1), R. Lewis (2)

(1) Syngenta Crop Protection, Greensboro, NC, U.S.A.; (2) Syngenta Crop Protection, Jealotts Hill, United Kingdom

Phytopathology 104(Suppl. 3):S3.144

Regulatory authorities around the world have developed approaches to evaluate and address potential effects related to perturbation of hormone systems in humans and wildlife by crop protection products. A number of test methods are available or are being developed to examine potential interactions with endocrine systems. Many new methods are designed to provide screening level data to enhance the speed at which decisions can be made. These methods include both computer based (in silico) prediction models and high throughput in vitro assays that when coupled with targeted whole animal test systems enable rapid assessment of potential interaction with the endocrine system. These approaches can be applied early in the product development strategy to help understand the mode or mechanism of action This presentation will provide context for evaluating endocrine disruption and discuss how new methods could be incorporated into disease control product design and selection.

\section{Myths and Realities of Biopesticides: Academic, Industry, and Grower Perspectives}

\author{
Optimizing use of biopesticides for successful, cost-effective plant disease \\ management in greenhouse vegetable production \\ M. BLEDSOE (1) \\ (1) Village Farms International, Heathrow, FL, U.S.A. \\ Phytopathology 104(Suppl. 3):S3.144
}

The greenhouse environmental conditions and culture systems that are used to produce maximum growth and yield of commercial vegetable crops also favor growth and development of many economically important pathogens and pests. Greenhouse growers have little margin for error in managing diseases to produce the high-quality fresh vegetable crops that the consumer market expects. Integrated disease management (IDM) programs utilizing biopesti- cide components have become essential to greenhouse growers to achieve effective control of vegetable crop diseases. This presentation will describe how proper selection, application, and timing of biopesticides have helped Village Farms and other growers fill efficacy gaps of conventional chemical products in IDM programs to produce affordable, high-quality, and safe greenhouse vegetables for the consumer market.

Development, marketing, support, and effective use of biopesticides in organic, sustainable, and conventional crop production M. S. KRAUSE (1)

(1) BioWorks, Inc., Victor, NY, U.S.A.

Phytopathology 104(Suppl. 3):S3.144

In many respects, biopesticides are developed, registered, and marketed for control of agricultural and horticultural crop diseases similarly to products with synthetic chemical active ingredients. Because many biopesticides 
contain active ingredients that are living organisms or are produced by living organisms, the activities, limitations, duration, stability, compatibilities, and other characteristics that determine efficacy of a biopesticide active ingredient can be greatly influenced by numerous biotic and abiotic factors. Hence, more technical information about a biopesticide is needed than with a conventional pesticide for developing formulations, best use practices, and guidance and other technical resources needed for growers to properly select and effectively use the product. Practical aspects and potential pitfalls of biopesticide development, registration, marketing, and technical support will be addressed and discussed.

Optimizing use of biopesticides for successful, cost-effective plant disease management in ornamentals production

R. MCGAUGHEY (1)

(1) Pioneer Gardens Inc., Deerfield, MA, U.S.A.

Phytopathology 104(Suppl. 3):S3.145

Biopesticide products can provide ornamentals growers cost-effective control of plant diseases. In order to achieve commercially acceptable disease control using biopesticides, growers must develop and implement crop production and disease management practices that go beyond calendar spray programs, reacting to diseases, and traditional plant culture. Practical experiences in the development and implementation of smart integrated disease management programs using commercial biopesticides, continuous crop monitoring, and good production practices will be presented and discussed.

\section{Soilborne biopesticides: Mechanisms, strengths, and limitations} B. MCSPADDEN GARDENER (1)

(1) The Ohio State University, Wooster, OH, U.S.A.

Phytopathology 104(Suppl. 3):S3.145

For nearly a century, human beings have been examining the use of soilborne biopesticides with an eye towards both reducing root diseases and increasing crop productivity. Throughout that long history, researchers have related the effects of microbial biopesticides to the ecological interactions among the applied antagonists, the targeted pathogens, and the crop host in the context of the crop production system. Reductionist approaches have revealed much about the individual components and the mechanisms by which they can contribute to plant health promotion. Such work is essential and must continue so new active ingredients can be discovered and vetted as inputs. However, it is also essential to step back once again to consider the degree to which we can successfully integrate various types of biopesticides into different production systems. Now, in the 21 st century, a rapidly expanding market of organic, biological, and chemical-intensive farmers aims to use microbial biopesticides more widely and more successfully. To do so, we all need to better understand and manage the ecology of the cropping systems into which biopesticides are to be applied. For soilborne biopesticides, several challenges to successful delivery and some possible solutions for enhancing crop responsiveness will be discussed.

Introduction to commercially available biopesticides and the biopesticide industry: History and current status

W. STONEMAN (1)

(1) Biopesticide Industry Alliance, McFarland, WI, U.S.A.

Phytopathology 104(Suppl. 3):S3.145

Biopesticides used for managing plant diseases have progressed over the past 30 years from obscure, quirky treatments of inconsistent quality and efficacy to user-friendly mainstream products with reliable quality and proven efficacy. Largely behind this progress are consistent improvements in technical understanding of existing and new biopesticide products, improved technology transfer and product commercialization models as well as growers' continuously expanding awareness and acceptance of biopesticides and their willingness to integrate them into disease management programs. The history and current status of the biopesticide industry will be described during this presentation. In addition, prospects and challenges for the future of biopesticides will also be discussed.

Foliar biopesticides: Mechanisms, strengths, and limitations S. ZHANG (1)

(1) Tropical Research and Education Center, University of Florida, Homestead, FL, U.S.A.

Phytopathology 104(Suppl. 3):S3.145

Biological control by biopesticides is an important component of integrated pest management and provides alternatives to the use of conventional chemicals. Prevention of pathogen infection or suppression of disease by biocontrol agents is contingent on their modes of action. It is well known that competition for nutrients and space by biocontrol agents is an important mechanism because certain pathogens are negatively infected by lack of nutrients in the infection court. Antibiosis and hyperparasitism are other mechanisms by which many pathogens are adversely affected. Resistance in host plants may be induced locally or systemically by live cells or dead cells of biocontrol agents, and induced resistance is usually effective against different pathogens. Reduction of the saprophytic ability and reducing spore dissemination by biocontrol agents are among other mechanisms. Lately, it is revealed that repressing pathogenicity factors of the pathogens is responsible for biocontrol. Practically, large-scale use of biocontrol particularly in the field is still limited because of inconsistency of performance. To improve the performance of biocontrol, integration of biocontrol with chemicals or application of mixed biocontrol agents each with different modes of action would be a promise. The overall goal of these suggested strategies is to reduce risk of uncontrolled disease epidemics and to increase confidence of growers in using biocontrol.

\section{Diseases of Plants}

\section{An Expanding Virome of Cultivated Plants: Home-Grown or Imported?}

With a little help from their 'friends': The worldwide emergence of geminiviruses

R. GILBERTSON (1)

(1) Department of Plant Pathology University of California-Davis, Davis, CA, U.S.A.

Phytopathology 104(Suppl. 3):S3.145

Geminiviruses possess a circular single-stranded DNA genome encapsidated within twinned quasi-isometric virions, and comprise one of the largest families of plant viruses. Most species are transmitted by the whitefly, Bemisia tabaci, and are in the genus Begomovirus. The emergence of begomoviruses is due to a high mutation rate and propensity for recombination, as well as help from a number of 'friends'. One is the $B$. tabaci biotype B, a polyphagous insect with a high reproductive rate that has spread throughout the world. This insect vector introduces indigenous begomoviruses from non-cultivated plants into crop plants, facilitating the local evolution of crop-infecting forms. Human beings have helped begomoviruses by the worldwide spread and cultivation of New World crops, which have provided susceptible hosts for viral emergence and evolution. The global movement of plant materials has inadvertently resulted in the spread of begomoviruses, including the monopartite Tomato yellow leaf curl virus (TYLCV) and those infecting sweet potatoes and ornamental plants.
Monopartite begomoviruses found an anonymous single-stranded DNA virus 'friend' that donated genomic components that became satellite DNAs. The betasatellite depends on the helper begomovirus for replication and spread and in return provides a powerful silencing suppressor essential for pathogenicity. Thus, these 'friends' have helped begomoviruses emerge as a major threat to worldwide food security.

Emergence, origins, and potential control points for new viruses affecting ornamental crops

J. HAMMOND (1)

(1) USDA-ARS, USNA, Floral and Nursery Plants Research Unit, Beltsville, MD, U.S.A.

Phytopathology 104(Suppl. 3):S3.145

The introduction of new species and varieties is important to the ornamentals industry, yet new materials bring risks of new viruses or viroids that may affect other ornamentals or even agronomic crops. Changes in production practices over recent decades also affect the introduction and prevalence of virus diseases; among these is a shift from seed production to large-scale vegetative propagation of many industry staples such as petunia, and changes of scale from local origin and production of relatively small numbers of plants to large-scale globally distributed production. Unrooted cuttings may be produced at one location, with rooting and plug production at a second facility, and finishing at a third location before distribution to a retail outlet. Distributed production facilitates introduction and dissemination of new 
viruses, and the transmission of viruses between diverse crops and different continents. A single mother plant can yield thousands of infected cuttings, which may not show visible symptoms before reaching flowering size at the wholesale or retail outlet. Recently-emerged viruses include Alternanthera mosaic virus, found in phlox in 1997 and now known to infect ornamentals in at least 17 diverse genera; Viola white distortion associated virus, a novel ilarvirus affecting pansies; and multiple carlaviruses. More sensitive, wide spectrum detection methods, applied early in the crop production cycle, may minimize new virus introduction and spread.

\section{Viroids: New and continuing risks to agriculture}

R. W. HAMMOND (1)

(1) USDA ARS MPPL, Beltsville, MD, U.S.A.

Phytopathology 104(Suppl. 3):S3.146

Viroids are single-stranded, covalently closed, circular, highly structured noncoding RNAs that cause disease in several economically important crop plants. Viroids replicate autonomously and move systemically in host plants with the aid of the host machinery. In addition to symptomatic infections, viroids also cause latent infections where there is no visual evidence of infection in the host, as is the case in many ornamentals; however, transfer to a susceptible host can result in devastating disease. Viroid infections have their origins from natural vegetation and infected seed and propagation materials. Once introduced, they are easily mechanically transmissible and have exhibited an expanding host range into susceptible crops. Viroid infections occur more often than widely appreciated and recent interceptions and outbreaks have prompted discussions regarding the expansion of import/export regulations of germplasm. Emerging viroid diseases in the Solanaceae (e. tomato and pepper) caused by seed-transmitted viroids (Potato spindle tuber viroid, Columnea latent viroid, Pepper chat viroid, Tomato chlorotic dwarf viroid, among others), and in vegetatively-propagated crops, are a threat to agriculture worldwide. Challenges facing industry and regulatory agencies include the use of appropriate detection, reporting, and control measures to maintain healthy crops.

\section{Major virus diseases of Vitis, where they originated from?}

\section{G. P. MARTELLI (1)}

(1) University Aldo Moro, Bari, Italy

Phytopathology 104(Suppl. 3):S3.146

Grapevines host more than 60 viruses, 25 of which are involved in the etiology of three major virus diseases: infectious degeneration/decline, leafroll and rugose wood. Except for decline, these diseases have a worldwide distribution which makes the identification of their site of origin an arduous exercise. Hints to this aim can be found in historical sources (bibliography, artworks, herbaria) and in the knowlege of disease ecology. Grapevine decline, the American counterpart of the European infectious degeneration, is largely confined to USA and Canada, is induced by American nepovirures (ToRSV, TRSV, PRMV), and is vectored by American Xiphinema species. Its North American origin contrasts with that of the other aforesaid disorders, which appear to have their roots in the Old World. The GFLV-induced fanleaf disease is the most relevant component of infectious degeneration, a nepoviral disease (ArMV, TBRV, SLRSV, RpRSV) restricted to continental Europe, and transmitted by local vectors. As to leafroll, early reddening of grape leaves is descrbed in old French and Italian literature, while the disease and some of its agents (GLRaV-1, GLRaV-3) were found in own-rooted vines from phylloxera-free countries with a millennial viticultural history. A comparable situation exists for rugose wood, a disease first described in Italy, whose symptoms and related agents (GVA, GVB) were found in countries with a long history of own-rooted grape cultivation.

Viruses of berry crops: Emerging, newly identified, and getting around R. R. MARTIN (1)

(1) USDA-ARS Horticultural Crops Research Unit, Corvallis, OR, U.S.A. Phytopathology 104(Suppl. 3):S3.146

Perennial crops offer great advantages to viruses in terms of adaptation and evolution since they avoid vector imposed evolutionary bottlenecks. There are 30 genera of plant viruses known to infect berry crops with many of the viruses recently identified. It is likely there will be 4 new virus genera based on these new viruses. There has been a rapid increase in production of blackberry and blueberry in the southeastern U.S. since the mid-1990s, and a lagging but parallel increase in the number viruses of these crops in the region. There are 8 viruses in the region new to blackberry, of which 6 are new to science. One of these is Blackberry virus $Y$, the type member of the genus Brambyvirus. Also in this region in blueberry, Blueberry necrotic ring blotch virus also new to science is proposed as a new genus, Blunervirus. In the Pacific Northwest, Raspberry latent virus, a novel reovirus has been characterized, for which the genus Raslavirus is proposed, as it is the first known plant reovirus transmitted by aphids. Again in this region, there is a new Caulimovirus in blueberry that has host sequences incorporated into its genome. Since many viruses are symptomless when they occur in single infections in these crops, disease control is the primary objective in fruiting fields rather than virus control. In contrast, virus control is critical in nurseries to minimize the long distance spread of these viruses to new regions, where they may form new virus complexes.

The origin and spread of viruses infecting vegetables and row cropsLessons to be learned from past decades

W. MENZEL (1)

(1) Leibniz Institute DSMZ - Plant Virus Department, Braunschweig, Germany

Phytopathology 104(Suppl. 3):S3.146

Intercontinental travel and trade has increased significantly in recent decades. Simultaneously, the number of emerging plant diseases has increased, posing a major threat to agricultural and horticultural production. In particular, many new viruses infecting crops of the plant families Solanaceae and Cucurbitaceae have been discovered in European and WANA countries in recent years. Frequently insect-vectored and seed transmitted viruses lead to significant problems, especially when they are also mechanically transmissible. Moreover, the vector species Bemisia tabaci can play an increasingly important role, considering future climatic changes. In this presentation, several current examples are presented and discussed. In order to minimize the spread of emerging viruses and potential crop losses early detection of virus diseases is critical. The availability of reliable data, validated diagnostic protocols and thoroughly characterized reference isolates is of crucial importance for diagnostic laboratories. The European initiative Q-bank (www.q-bank.eu), a web-portal focusing on species that are regulated in the European Union, aims to make such information available with the unique feature that it is linked to specimens present in publicly available physical collections. This will support efforts to limit the introduction and spread of diseases more effectively and to generally allow a faster response to new challenges in plant protection in a globalized environment.

\section{Boxwood Blight: Confronting an Emerging Disease Through Collaborative Connections}

\section{Boxin' the blight: The green industry perspective $\&$ discussion session} J. F. BISCHOFF (1), C. L. Palmer (2), D. M. Benson (3)

(1) AmericanHort, Washington, DC, U.S.A.; (2) IR-4, Rutgers University, Princeton, NJ, U.S.A.; (3) North Carolina State University, Raleigh, NC, U.S.A. Phytopathology 104(Suppl. 3):S3.146

The 2011 discovery of Boxwood Blight in the United States sent shock waves through the nursery industry. Boxwood sales represent over $\$ 100$ million per year, making it second only to holly in the broadleaf everygreen category. As of 2009 growers nationally had approximately $\$ 170$ million in boxwood in the ground, money already invested, expecting there to be a market for the crop in the coming years. With the health and marketabilty of a cornerstone crop like boxwood in question the industry needed answers quickly and through industry, academic, and government collaboration we put ourselves on a path towards better understanding our options for the future.
Boxwood blight: Identify, know, and conquer

J. A. CROUCH (1), B. Gehesquiere (2), H. Guo (3), J. Hebert (1), K. Heungens (2), M. Malapi-Wight (1), R. E. Marra (4), R. Olsen (3), M. Pooler (3), Y. Rivera (1), C. Thammina (3)

(1) USDA-ARS, Systematic Mycology \& Microbiology Lab, Beltsville, MD, U.S.A.; (2) Instituut voor Landbouw- en VisserijOnderzoek (ILVO), Merelbeke, Belgium; (3) U.S. National Arboretum, USDA-ARS, Beltsville, MD, U.S.A.; (4) The Connecticut Agricultural Experiment Station, New Haven, CT, U.S.A. Phytopathology 104(Suppl. 3):S3.146

Boxwood blight is the latest in a long line of exotic plant diseases to threaten the horticulture industry in North America and Europe. The origin of boxwood blight is unknown. There are no reports of the causal fungus prior to the discovery of a then undescribed Calonectria species in the United Kingdom in the 1990s. A decade later, boxwood blight disease was widespread across Western Europe and New Zealand. The fall of 2011 marked the first disease sightings in North America. In this talk, we will present recent advances in the boxwood blight pathosystem in the areas of pathogen diversity, genomics and biogeography, host diversity and breeding for resistance, the host/pathogen 
interaction, and the development of new diagnostic methods. Tools brought to bear on this system include AFLP and SSR-based population studies of $>500$ isolates collected globally 1998-2013, comparative genomic analyses of fifteen diverse Calonectria pseudonaviculata isolates, and host diversity assessments using SEM, phylogenetic and SSR analyses. A suite of detection tools - including LAMP, conventional and real-time PCR - provide early pathogen detection, identification of mating gene frequencies, and identification of phenotypically diverse lineages. Collectively, findings from this work are beginning to provide a broader understanding of boxwood blight, and generate a toolkit of knowledge, resources and infrastructure needed to support long-term, cost effective disease management.

\section{Survival and detection of the boxwood blight pathogen in soil}

N. Dart (1), N. SHISHKOFF (2)

(1) Virginia Department of Agriculture and Consumer Services, Richmond, VA, U.S.A.; (2) FDWSRU/ARS/USDA, Frederick, MD, U.S.A.

Phytopathology 104(Suppl. 3):S3.147

While many Calonectria spp. have epidemiologically significant soil phases, little research has investigated the soil phase of $C$. pseudonaviculata. We will discuss an ongoing experiment to determine survival of the pathogen and the invention of a soil detection assay. Survival was investigated in leaves, twigs, and as discrete microsclerotia in sand at two moisture levels and 5 temperatures $(-10,0,10,20$ and $30 \mathrm{C})$; after one year, sporulation still occurred on leaves, twigs and from microsclerotia incubated at 0,10 , and $20 \mathrm{C}$. Plant tissue and microsclerotia incubated at -10 and $30 \mathrm{C}$ rapidly (within 100 days) lost the ability to sporulate or produce mycelium. A leaf disc bioassay for quantifying and detecting C. pseudonaviculata in soil was tested side-by-side with a standard soil plating assay for Calonectria. When compared using three distinct soil types (sand-loam, silt-loam, and sand-peat potting media) over a range of inoculum densities, the optimal incubation time for leaving leaf discs in soil when baiting $C$. pseudonaviculata was $96 \mathrm{hrs}$. The optimal soil moisture for the bioassay was $1000 \%$ field capacity (soil flooded with $2-4$ $\mathrm{mm}$ water). The leaf disc bioassay was able to detect C. pseudonaviculata at levels as low as 1 microsclerotium/g soil while the soil plating bioassay was unable to detect the pathogen below inoculum levels of 10 microsclerotia/g soil. Soil type had a significant impact on the sensitivity of both assays.

Boxwood blight and the dawn of a research collaboration

S. M. DOUGLAS (1), D. M. Benson (2), J. A. Crouch (3), N. L. Dart (4), M. L. Daughtrey (5), C. Hong (6), K. L. Ivors (2), J. A. LaMondia (7), R. E. Marra (1), C. L. Palmer (8), N. Shishkoff (9)

(1) The Connecticut Agricultural Experiment Station, New Haven, CT, U.S.A.; (2) North Carolina State University, Raleigh, NC, U.S.A.; (3) USDA ARS, Systematic Mycology and Microbiology Laboratory, Beltsville, MD, U.S.A.; (4) Virginia Department of Agriculture and Consumer Services, Richmond, VA, U.S.A.; (5) Cornell University, LIHREC, Riverhead, NY, U.S.A.; (6) Virginia Tech Hampton Roads AREC, Virginia Beach, VA, U.S.A.; (7) The Connecticut Agricultural Experiment Station, Windsor, CT, U.S.A.; (8) IR-4 HQ, Rutgers University, Princeton, NJ, U.S.A.; (9) USDA ARS FDWSRU, Frederick, MD, U.S.A.

Phytopathology 104(Suppl. 3):S3.147

Boxwood blight, caused by Calonectria pseudonaviculata, emerged as a destructive disease first detected in North America in October 2011. Initially observed in the U.K. in the 1990s and now considered endemic throughout Europe, the disease has been reported from nurseries and landscapes in 12 U.S. states and 3 Canadian provinces, where it has caused substantial economic loss. Affected plants develop leaf and stem lesions that can result in severe defoliation, dieback, disfigurement, and plant death. In addition to the threat to the boxwood industry, this disease represents a potential peril to historically and culturally important boxwood plantings. Government and university scientists, growers, and regulators in the U.S. responded to this threat with an unprecedented collaboration to ensure a focused, coordinated effort toward improved understanding and management of this disease.
Collaboration among research groups has provided a robust common platform that accelerated discovery on a scale not possible from any individual laboratory. Information was rapidly generated on sanitizers, fungicides, resistant cultivars, and field residue flaming for best management guides delivered through extension outreach. Additional outcomes included bioassay and molecular tools for detection, improved understanding of environmental effects on survival, deciphering the population genetics of the pathogen, as well as other mitigation practices for disease management.

The show must go on: Boxwood and beyond

M. Ganci (1), D. M. Benson (1), J. A. LaMondia (2), K. IVORS (1)

(1) North Carolina State University, Raleigh, NC, U.S.A.; (2) The Connecticut Agricultural Experiment Station, Windsor, CT, U.S.A.

Phytopathology 104(Suppl. 3):S3.147

Boxwood blight is a foliar disease caused by the fungus Calonectria pseudonaviculata. As infection progresses, foliar lesions often expand, resulting in leaf blighting and defoliation. While boxwood blight is a significant threat to established plantings of the commonly grown cultivars American (B. sempervirens) and English (B. sempervirens 'Suffruticosa'), the vast diversity in the genus Buxus should lead to the identification of disease resistance. Outdoor trials were conducted during the growing seasons of 2012 and 2013 to evaluate the susceptibility of 51 commercial Buxus cultivars to boxwood blight in Mills River, NC. Results indicate a wide range in susceptibility to $C$. pseudonaviculata. In general, $B$. sempervirens cultivars experienced more blighting and defoliation than B. microphylla and B. sinica var. insularis cultivars. Canopy density and height also influenced susceptibility. In Connecticut trials, Korean (B. sinica var. insularis) and $B$. microphylla 'Winter Gem' were the least susceptible, American and English were the most susceptible, and Green Mountain and Green Velvet ( $B$. sempervirens $\times$ B. sinica) were intermediate. Although the partially-resistant varieties we identified showed minimal symptom development, these plants were capable of harboring the pathogen and providing inoculum for susceptible cultivars nearby. Thus, the use of partially-resistant cultivars is just one part of an integrated management approach.

Kryptonite for boxwood blight: Management with fungicides and sanitizers J. A. LAMONDIA (1), S. M. Douglas (2), K. L. Ivors (3), N. Shishkoff (4)

(1) The Connecticut Agricultural Experiment Station, Windsor, CT, U.S.A.; (2) The Connecticut Agricultural Experiment Station, New Haven, CT, U.S.A.; (3) North Carolina State University, Raleigh, NC, U.S.A.; (4) USDA ARS FDWSRU, Frederick, MD, U.S.A.

Phytopathology 104(Suppl. 3):S3.147

Trials were conducted to evaluate in vitro and in vivo fungicide activity and sanitizer efficacy against the boxwood blight pathogen Calonectria pseudonaviculata. Twenty fungicides from 13 FRAC groups were evaluated for effects on conidial germination and mycelial growth using in vitro assays. Boxwood plants were inoculated 24 to $48 \mathrm{hr}$ after application of fungicides with in vitro activity. Disease progressed over six weeks from leaf and stem lesions to defoliation. Products containing propiconazole, myclobutanil, thiophanate-methyl, fludioxonil, pyraclostrobin, kresoxim-methyl, and chlorothalonil had significant efficacy with $90 \%$ to nearly $100 \%$ control when applied preventatively. Systemic plus protectant fungicides in a single application resulted in superior disease control compared to systemic fungicides alone. Sanitizers were assessed for their effects on mycelial growth, conidial germination, and microsclerotia using in vitro assays with serial dilutions and contact times. Depending on fungal structure and experimental conditions, sanitizers including O-benzyl-p-chlorophenol, $70 \%$ ethanol, sodium hypochlorite, hydrogen dioxide, hydrogen peroxide, peroxyacetic acid and octanic acid were effective with contact times as short as five minutes. These results will help refine current best management practices. Management of boxwood blight will rely on integrated best management practices, sanitation, cultural controls, cultivar resistance and fungicide application.

\section{Destructive Tree Diseases Associated with Ambrosia/ Bark Beetles: Black Swan Events in Tree Pathology}

Pine-specific beetle-fungus symbioses in Asia that have not yet invaded the US: Empirical assessment of threat

J. HULCR (1), C. Bateman (1), W. Bo (2)

(1) University of Florida, Gainesville, FL, U.S.A.; (2) Chinese Academy of

Sciences, Xishuangbanna, China

Phytopathology 104(Suppl. 3):S3.147
Introduced tree diseases vectored by wood borers nearly eradicated a number of American tree species, including elms and redbays, and are now threatening crops such as walnuts or avocados. A similar future epidemic of American pines would result in an unprecedented disaster. We developed a safe and feasible approach for assessing the threat of exotic pine boring insects associated with fungi before their establishment in the US. Our data will enable federal agencies to distinguish harmless from actionable species in case of introduction. Our screening consists of five steps: 1) Collect target species abroad, using bait trees and traps. 2) Isolate fungal associates (potential pathogens); the vectors are discarded. 3) Fungal isolates are shipped 
to the US. 4) Assemble genotypes of each of the 3 most important pines in the SE US: loblolly, slash, and longleaf. 5) Each pine genotype is inoculated with each fungus to test for pathogenicity. Pathogenicity is fitted to one of three models of interactions between exotic beetle-borne tree pathogens and American trees: 1) no effect, 2) locally pathogenic, 3) systemic pathogens. The screening approach has been successfully tested in 2013 in China. It yielded data for three beetle-fungus complexes: Fungi of Tomicus minor: no pathogenicity; fungi of Xyleborus pinicola: no pathogenicity; fungi of Ips chinensis: mildly pathogenic to loblolly pine, should be monitored if detected. None of the three species is an imminent threat.

Rapid crown decline and mortality of hickory associated with numerous Ceratocystis smalleyi infections and mass attacks by the hickory bark beetle J. JUZWIK (1), J. H. Park (2)

(1) U.S. Forest Service, St. Paul, MN, U.S.A.; (2) Korea Forest Research Institute, Seoul, South Korea

Phytopathology 104(Suppl. 3):S3.148

Episodes of widespread and locally severe mortality of hickory (Carya spp.) have occurred periodically in the eastern USA since the early part of the 20th century. Historically, this mortality was attributed to outbreaks of the hickory bark beetle (Hbb) (Scolytus quadrispinosus) during extended periods of drought. Observation of discolored wood and bark cankers on Hbb-attacked hickories in the early 1990's led to discovery of a new Ceratocystis species subsequently described as $C$. smalleyi. In an observational field study, tens to hundreds of bark cankers with xylem lesions and hundreds to thousands of bark beetle attacks were documented on main stems of C. cordiformis (bitternut hickory) with actively declining crowns. Hbb galleries or entry/exit holes were found within 92 to $94 \%$ of the xylem lesions. The pathogen was also isolated from a high percentage of Hbb initiating attack on stems of hickory trees. Xylem sap flow rates were significantly lower for C. smalleyi inoculated bitternut hickory trees than water controls in field studies. The numerous cankers and xylem dysfunction resulting from multiple infections suggests the fungus plays an important role in rapid crown decline. It is hypothesized that the Hbb-C. smalleyi interaction leads to rapid tree wilt and death, especially following predisposing abiotic events. This bark beetlefungal pathogen complex may have been a black swan event 115 -plus years ago, but it does not resemble one today.

\section{New perspectives on thousand cankers disease of walnut}

M. T. KASSON (1), G. J. Griffin (2), D. M. Geiser (3), E. S. O’Neal (3), J. Juzwik (4), S. Reed (5), N. Tisserat (6), R. M. Turcotte (7), D. K. Martin (7), D. D. Davis (3), K. A. Fenstermacher (3), K. O'Donnell (8)

(1) West Virginia University, Morgantown, WV, U.S.A.; (2) Virginia Tech, Blacksburg, VA, U.S.A.; (3) Pennsylvania State University, University Park, PA, U.S.A.; (4) USDA Forest Service, St. Paul, MN, U.S.A.; (5) University of Missouri, Columbia, MO, U.S.A.; (6) Colorado State University, Fort Collins, CO, U.S.A.; (7) USDA Forest Service, Morgantown, WV, U.S.A.; (8) USDA ARS NCAUR, Peoria, IL, U.S.A.

Phytopathology 104(Suppl. 3):S3.148

Thousand Cankers Disease (TCD) is a new disease of black walnut (Juglans nigra) caused by the fungus Geosmithia morbida, a symbiont of the walnut twig beetle (WTB, Pityophthorus juglandis). Members of the Fusarium solani species complex (FSSC) have also been implicated in TCD in Colorado, but little is known regarding their phylogenetic diversity and potential role in TCD. To resolve their diversity, we sampled 127 cankers and 30 beetles from 12 tree species both inside and outside confirmed TCD locations, including 105 isolates from Juglans spp., 75 of which were from confirmed TCD locations. A 3-locus DNA sequence dataset was constructed to assess the phylogenetic diversity of FSSC from various substrates found both inside and outside TCD areas. Multilocus typing identified high genetic diversity spanning $15 \mathrm{FSSC}$ species, eight of which were recovered from $>1$ tree host. Isolates from five phylogenetic species were exclusive to black walnut including FSSC 9, 15 and 25, together with two putatively novel FSSC species. Overall, 99/105 of the FSSC typed from Juglans sp. represented 36 newly discovered haplotypes that were distributed among 13 FSSC species. Sixteen of the haplotypes were exclusive to areas with TCD, 18 to areas without TCD; only two haplotypes were found in both areas. Although certain FSSC species were abundant across the landscape on multiple hosts, these data suggest that haplotypes associated with TCD may be novel and exclusive to those areas.

\section{Ambrosia and bark beetle-associated tree diseases: An overview}

R. PLOETZ (1)

(1) University of Florida, Homestead, FL, U.S.A.

Phytopathology 104(Suppl. 3):S3.148

Diseases that are associated with ambrosia and bark beetles comprise some of the most significant problems that have emerged on trees in the last century. They are caused by fungi in the Ophiostomatales, Microascales and Hypocreales, and have vectors in the Scolytinae (ambrosia and bark beetles) and Platypodinae (ambrosia beetles) subfamilies of the Curculionidae (Coleoptera). Some of these problems, such as Dutch elm disease (DED), have been extensively researched, whereas others are poorly understood; significant data gaps exist for the ecology, epidemiology, and management of most of these diseases. The emergence and unexpected importance of these problems are discussed. An underlying factor in most of the interactions is the absence of a coevolved history between the so-called "naive" or "new encounter" host trees and the pathogens and/or beetles. For the ambrosia beetles, these interactions are associated with susceptibility to what are typically benign fungi and atypical relationships with healthy trees (ambrosia beetles favor trees that are dead or stressed). Interestingly, the pathogens for both the ambrosia and bark beetle-associated diseases often have symbiotic relationships with the insects that are not based on phytopathogenicity. Some of the most alarming and damaging of these diseases are considered during this session as "black swan events."

\section{Laurel wilt disease: An exceptional Black Swan event}

J. A. SMITH (1), R. C. Ploetz (2), J. Hulcr (1), J. McCutcheon (3), T. J. Dreaden (1), M. A. Hughes (1), D. Spence (4), K. Shin (1), S. Inch (5), J. Ploetz (2), A. Campbell (6)

(1) School of Forest Resources and Conservation, University of Florida, Gainesville, FL, U.S.A.; (2) Tropical Research and Education Center, University of Florida, Homestead, FL, U.S.A.; (3) University of Montana, Missoula, MT, U.S.A.; (4) Florida Native Landscapes, Palm Coast, FL, U.S.A.; (5) USDA-Agricultural Research Service, Ft. Pierce, FL, U.S.A.; (6) Department of Plant Pathology, University of Florida, Gainesville, FL, U.S.A. Phytopathology 104(Suppl. 3):S3.148

Ambrosia beetles normally attack weak or dying trees where they cultivate and feed on their typically non-pathogenic fungal symbionts. Native and cultivated trees in the Lauraceae in the southeastern US are being devastated by laurel wilt (LW), caused by the exotic fungal pathogen, Raffaelea lauricola which is transmitted to trees by the Asian redbay ambrosia beetle (Xyleborus glabratus). In little more than a decade, LW has killed hundreds of millions of redbay trees and threatens the avocado industries in Florida (valued at $>\$ 60$ million/year) and California (\$400 million). The pathogen is unique since it is highly virulent to host trees, with as few as 100 conidia being sufficient to induce disease. Microscopic observations and studies with secondary metabolites indicate that hosts over-react to the presence of the pathogen leading to vascular dysfunction, but toxins are likely not involved in pathogenesis. Genetic analyses of $R$. lauricola indicate that a single clone occurs in the USA and comparisons of microsattelite loci of the pathogen in the USA indicate a close match with isolates in Taiwan. Lateral transfer of the pathogen to other ambrosia beetle species has been observed in Florida. Strategies to manage LW focus on use of systemic fungicides, early detection and sanitation in avocado orchards and host resistance. Genomic analyses $R$. lauricola and closely related, nonpathogenic fungal species are underway to elucidate modes of pathogenicity.

\section{Ecology and Epidemiology}

\section{4th I. E. Melhus Graduate Student Symposium: New Contributions to Epidemiology and Plant Health}

New approaches to assess coast live oak resistance before infection by the invasive pathogen Phytophthora ramorum

A. O. CONRAD (1), L. Rodriguez-Saona (1), B. McPherson (2), D. Wood (2), P. Bonello (1)
(1) The Ohio State University, Columbus, OH, U.S.A.; (2) University of California, Berkeley, Berkeley, CA, U.S.A.

Phytopathology 104(Suppl. 3):S3.148

Coast live oak (Quercus agrifolia, CLO), an endemic species in coastal California forests, is highly susceptible to the invasive pathogen Phytophthora ramorum, the causal agent of sudden oak death (SOD). While putatively resistant CLO have been observed, there are few methods for identifying 
resistant trees and most rely on symptom expression following infection. The objectives of this study were to determine if CLO resistance and survival can be assessed pre-infection using (1) phloem phenolic biomarkers and (2) Fourier transform infrared (FT-IR) spectroscopy of phloem phenolic extracts combined with chemometric analysis. Phloem was collected from trees prior to inoculation with the pathogen, and symptom development and survival were monitored following infection. Constitutive phenolic biomarkers were significant predictors of survival (Cox Proportional Hazards, $P=0.048$; Weibull survival analysis, $P=0.015$ ). Analysis of FT-IR spectral data by soft independent modeling of class analogy identified two spectral ranges, associated primarily with carbonyl groups, which could discriminate between resistant and susceptible CLO before infection. Identification of resistant CLO in the landscape may be useful for protecting areas at risk of becoming affected by SOD or in breeding resistant germplasm. Furthermore, these new approaches for identifying resistant trees could be useful for the study and management of other emerging forests diseases and pest infestations.

\section{Forecasting infection risk - a tool for late bight management}

I. M. SMALL (1), L. Joseph (2), P. Julian (3), H. S. Mayton (4), P. D. Roberts (3), D. Shtienberg (5), W. E. Fry (1)

(1) Dept. Plant Pathology and Plant-Microbe Biology, Cornell University, Ithaca, NY, U.S.A.; (2) Cornell University, Ithaca, NY, U.S.A.; (3) University of Florida, Southwest Florida Research and Education Center, Immokalee, FL, U.S.A.; (4) Dept. Plant Biology and Pathology School of Environmental and Biological Sciences, Rutgers University, The State University of New Jersey, New Brunswick, NJ, U.S.A.; (5) Dept. Plant Pathology and Weed Research, ARO, the Volcani Center, Bet-Dagan, Israel Phytopathology 104(Suppl. 3):S3.149

An algorithm to predict infection-risk for potato or tomato late-blight has been developed using data obtained experimentally and from the published literature. The algorithm calculates the favorability of weather conditions for sporulation and release at the source, survival of sporangia in transit, and subsequent infection of host tissue at the target site. Observed and forecast weather data serve as inputs and include: temperature, relative humidity, wind speed and direction, and solar radiation. Additionally, proximity of the target to an inoculum source is used. For each potential risk period, independent indices are calculated for sporulation, dispersal and survival of sporangia, and for subsequent infection of target host tissue. These indices are then integrated to provide an overall risk index. Datasets of observed late blight epidemics from the US and Israel were utilized to validate the algorithm. Because the algorithm uses future as well as historical weather, it enables users to take precautionary measures against late blight. Preliminary experiments suggest that the algorithm could be used to enhance the efficiency of disease management practices through the prediction of "high infection-risk" periods.

\section{Modes of seed infection by Clavibacter michiganensis subsp. michiganensis} and population diversity in New York

M. A. TANCOS (1), C. D. Smart (1)

(1) Cornell University, Geneva, NY, U.S.A.

Phytopathology 104(Suppl. 3):S3.149

Bacterial canker, caused by Clavibacter michiganensis subsp. michiganensis, is an economically devastating seed-borne pathogen that inflicts considerable damage throughout all major tomato-producing nations. Understanding the movement of $C$. michiganensis subsp. michiganensis both microscopically and geographically will help characterize population diversity, virulence, and modes of infection. In order to investigate the mode of seed infection, New York C. michiganensis subsp. michiganensis field strains were stably transformed with eGFP. C. michiganensis subsp. michiganensis was able to access the developing seeds either i) systemically through the xylem and/or ii) externally by entering fruit through lesions on the pericarp. C. michiganensis subsp. michiganensis cells were located within the developing seed, endosperm, and funiculus, although at relatively low levels compared with the large numbers of cells observed in xylem and pericarp cells; thereby, highlighting the difficulty in detecting and eradicating small initial pathogen populations within seed lots. Furthermore, multilocus sequencing typing revealed a high level of $C$. michiganensis subsp. michiganensis diversity in New York with approximately 20 unique sequence types. Unique differences were also evident in virulence and plasmid profiles.

Staying one step ahead of a pathogen: Hop powdery mildew in the Pacific Northwest

S. WOLFENBARGER (1), M. C. Twomey (1), D. M. Gadoury (2), B. J. Knaus (3), N. J. Grunwald (4), D. H. Gent (5)

(1) Oregon State University, Department of Botany and Plant Pathology, Corvallis, OR, U.S.A.; (2) Cornell University, Department of Plant Pathology and Plant-Microbe Biology, Geneva, NY, U.S.A.; (3) US Department of Agriculture-Agricultural Research Service, Horticultural Crop Research Unit, Corvallis, OR, U.S.A.; (4) Oregon State University, Department of Botany and Plant Pathology, US Department of Agriculture-Agricultural Research Service, Horticultural Crop Research Unit, Corvallis, OR, U.S.A.; (5) Oregon State University, Department of Botany and Plant Pathology, US Department of Agriculture-Agricultural Research Service, Forage Seed and Cereal Research Unit, Corvallis, OR, U.S.A.

Phytopathology 104(Suppl. 3):S3.149

In the Pacific Northwestern region (PNW) of the United States, hop powdery mildew, caused by Podosphaera macularis, is not known to produce ascocarps despite forming ascocarps in Europe and the eastern U.S. Sexual reproduction in $P$. macularis and other Ascomycetes is regulated by the mating type locus MAT1. Pairing of the two locus idiomorphs (MAT1-1 and MAT1-2) is required for sexual reproduction. Thus, presence of a single mating type idiomorph in $P$. macularis populations of the PNW would explain the absence of ascocarps. We developed a PCR assay to identify both MAT1-1 and MATI-2 in P. macularis. Matings with MATI-2 isolates and PCR assays confirmed heterothallism and exclusive presence of MAT1-1 within 317 PNW isolates of $P$. macularis collected in 2012 and 2013. In contrast, the frequency of both idiomorphs among 56 isolates gathered from the eastern United States and Europe approximated a 1:1 ratio (Chi square $P=0.806$ ). Controlled environment studies indicated that late season temperatures in the PNW are conducive to ascocarp formation. Microscopy and differential staining revealed a process of ascocarp development and ascospore maturation similar to that reported for other powdery mildews. Our findings can explain the absence of ascocarps in PNW, and have important implications for management of hop powdery mildew. Quarantine regulations in the PNW have been revised to delay, if not prevent the introduction of the second mating type.

\section{Food Security: Role of Plant Pathology}

How important are plant diseases as major causes of food insecurity? C. A. HOLLIER (1)

(1) Louisiana State University Agricultural Center, Baton Rouge, LA, U.S.A. Phytopathology 104(Suppl. 3):S3.149

Plant disease is a major risk factor in crop production and leads to food insecurity globally. Historical observations and current research aid in the understanding of the disease process and help with disease management planning and prevention. As a means of management, risk factors should be recognized from the onset and reduced as much as is reasonable through an integrated management system designed for known risk factors. These integrated management approaches begin with a plan made prior to planting and is implemented throughout the growing season. The quantity of pathogens, the environments in which they thrive, our lack of understanding of some disease cycles and their impact on the global food and fiber crops, make it impossible to manage all diseases adequately. The global impact of plant diseases leads to inadequate food resources for many people each day much less for the long term. This presentation will present the problem of food shortages globally, why they exist due to the influence of plant diseases and examples of epidemics that lead to food insecurity.

Development of food security through academic excellence via international cooperation

V. M. JIMENEZ (1), A. Murillo Williams (2)

(1) Seed and Grain Research Center (CIGRAS). University of Costa Rica, San Pedro, Costa Rica; (2) Universidad de Costa Rica, San Pedro, Costa Rica Phytopathology 104(Suppl. 3):S3.149

This project is in the frame of an Exceed program from the German Academic Exchange Service (DAAD), funded by the Federal Ministry for Economic Cooperation and Development, which involves activities with seven coordinating institutions around the world, including the Food Security Center based at the University of Hohenheim in Germany. As the coordinating institution for Latin America since 2009, the University of Costa Rica has fostered collaboration and knowledge development and transfer through short courses, regional seminars and workshops, summer schools and short-term $\mathrm{Ph}$.D. and postdoc stays abroad. More than 200 graduate students, postdocs 
and young scientists from over 15 developing countries from Latin America, Asia and Africa have benefited from these activities. The success of this program can also be seen in the development of new research projects; for example, the conservation and propagation of peach palm (pejibaye), a native plant that has a high nutritional value, jointly between Costa Rica and Brazil, and the use of underutilized Latin American sources of carotenoids for nutritional and health improvement in developing countries, concerning Costa Rica and Germany.

Environmental interactions and multiple forcing leading to shifts and variability of crop yield losses

S. SAVARY (1)

(1) INRA, Castanet Tolosan Cedex, France

Phytopathology 104(Suppl. 3):S3.150

Crop yield losses (YL) result from the dynamic interactions between agrophysiological processes and damage mechanisms. The former translate into levels of attainable yield (Ya), which are reflections of shifting production situations (PS). The latter depend on the biological diversity of harmful organisms leading to injury profiles (IP), which also depend on PS. Complex interactions are therefore at play in many cases. PS components include technology shifts (T), labor availability (L), water supply (W), mineral fertilizers $(\mathrm{F})$, pesticides $(\mathrm{P})$, and varietal improvement $(\mathrm{V})$. Agricultural adaptation to increasing food, feed, fiber, and energy demand is making use of various combinations of these components, some of them being directly dependent on climate change (C). For wheat in France, shifts in PS (F, P, V) lead to small Ya variation, and to less diverse, weaker PSs, translating in reduced YL. For lowland rice in Asia, highly variable PSs (C, T, L, W, F, P, V) correspond to large differences in Ya (increases or decreases), and very different IPs however translating into similar YL. Groundnut in West Africa, by contrast, may experience strong increase in Ya from improved PS (T, L, F), at the cost of intensified IP and higher YL. A broad framework for YL analysis is presented, showing the need and the value of a systems-based crop health assessment, as novel production systems are being designed for a growing world population under global change.

Loss and wastage in the food supply chain caused by microbes

T. V. SUSLOW (1), E. J. Mitcham (1)

(1) University of California, Davis, CA, U.S.A.

Phytopathology 104(Suppl. 3):S3.150

Renewed energy directed towards understanding global systems for food production, handling, distribution in relation to human health has sparked multiple initiatives for solutions to food insecurities. Projections for world population to reach nine billion by 2050 underscore the urgent need for system-wide reforms in supply-chain management and integration. Suggested solutions mostly involve pre-farm gate improvements in land utilization and yield. Seemingly on the sidelines, immediate and long-term gains in food security and food distribution equity are attainable by reducing postharvest losses. It has been estimated that postharvest losses of perishable horticultural foods routinely averages $12 \%$ from farm-gate to distribution and $20 \%$ at point of preparation and consumption in developed countries. In many developing and economically-disadvantaged countries, post farm-gate losses exceed $40 \%$. Postharvest losses of more stable agronomic crops, such as grains, have annual losses of $17 \%$. Without question, plant pathogens play an important role in preharvest crop losses and some carry-forward to manifestations of postharvest defect or decay. Some pathogens are not active until post-maturity ripening. This presentation will emphasize spoilage and decay and opportunities for substantial gains in food security within a framework of principles of postharvest biology and technology, emerging innovations for developing countries, and novel approaches to extending knowledge.

The multiple dimensions of food security and their challenges P. S. TENG (1)

(1) National Institute of Education, Nanyang Technological University, Singapore, Singapore

Phytopathology 104(Suppl. 3):S3.150

Food security (FS) encompasses food availability (production, imports and reserves), physical access (transport, logistics and supply chains), economic access to food (food pricing, economic status of population) and food utilization (food quality and safety), all underpinned by stability. Each dimension may be affected singly or interactively by any of a number of transient (e.g. disease outbreak in one season) or chronic (e.g. endemic diseases) factors. Plant pathogens directly affect production, imports, reserves, food quality and safety. However, many other factors affect FS, such as demographics (urbanization, diet change, ageing and declining farmer population), degradation of the natural resource base (soil and water), declining crop productivity growth, climate change and unsupportive agricultural policies. Ensuring food security therefore requires multi-disciplinary, multisectoral approaches to address all four FS dimensions. In tropical regions, diseases have chronically been yield reducing and cause crops not to achieve their yield potential in most years while in outbreak years have disrupted exports. Losses in storage and during processing, transport and retailing account for further threats to the stability of food availability. Microbial effects on food quality and safety, and the use of biotechnology have precipitated international efforts at harmonizing techniques and regulations to address the 'physical access' and 'utilization' aspects of FS.

\section{Interconnected Lifecycles: Multitrophic Interactions Between Plants, Pathogens, and Insects}

Characterizing the interaction between salt-stressed soybeans, vira infection, and vector performance

A. G. LANEY (1), K. L. Korth (1)

(1) University of Arkansas, Fayetteville, AR, U.S.A.

Phytopathology 104(Suppl. 3):S3.150

Crop damage due to salt stress is an increasing problem in agriculture worldwide. Soybean, Glycine max, genotypes differ in their ability to tolerate salt stress. Cultivars that limit the amount of chloride in foliar tissue are more salt tolerant and are called chloride excluders, whereas those that cannot are salt sensitive and termed chloride includers. An excluder, cv. Manokin, and includer, cv. Clark, were subjected to salt stress, Soybean mosaic virus infection, and feeding by Aphis glycines to test the impact of single and multiple stresses on aphid performance and plant responses. Soybeans were mechanically inoculated with SMV and salt stressed by flooding daily after systemic virus symptoms were observed. After 7 days, three third-instar aphids were caged on treated and non-treated plants. After two weeks, aphid populations were counted and static headspace volatiles were analyzed using GC-MS. Untreated plants supported significantly higher aphid populations than salt stressed and/or SMV-infected soybeans. Soybeans that were both salt stressed and infected with SMV had significantly smaller aphid populations than other treatment/virus combinations. Both 3-hexen-1-ol and 1-octen-3-ol were aphid induced but levels altered by salt stress and SMV. For example, both treatments reduced 1-octen-3-ol levels in Manokin. This suggests that the interaction between virus, vector, host and environment could potentially impact the epidemiology of SMV in the field.
A tale of how phytoplasma effectors alter plant-pathogen-insect interactions: It's a mad MADS world

A. M. MACLEAN (1), Z. Orlovskis (1), A. Sugio (1), H. Kingdom Gibbard (1), S. A. Hogenhout (1)

(1) John Innes Centre, Norwich, United Kingdom

Phytopathology 104(Suppl. 3):S3.150

Pathogens that rely upon multiple hosts to complete their life cycles often modify behavior and development of these hosts to coerce them into improving pathogen fitness. Host coercion is particularly important for obligate biotrophs that are reliant upon their hosts for survival. Phytoplasma are obligate phytopathogens that are transmitted by phloem-feeding insects such as leafhoppers. We wish to elucidate the mechanisms by which Aster Yellows phytoplasma strain Witches' Broom (AY-WB) modulates the development of plants to make these more attractive to the AY-WB insect vector Macrosteles quadrilineatus. We identify two novel AY-WB effector proteins - SAP11 and SAP54 - that target highly conserved host processes to transform phytoplasma-infected plants into preferred sites for leafhopper ovipositioning. We show that SAP11 acts to destabilize members of the TCP family of transcription factors, thereby suppressing jasmonate-mediated defence against insects. In contrast, SAP54 initiates the degradation of MADS-domain transcription factors, transforming fertile flowers into sterile leaf-like structures. M. quadrilineatus produce an increased number of nymphs on SAP11- and SAP54-expressing Arabidopsis, indicating that these effectors have the ability to modulate plant-insect interactions. Thus, an obligate bacterial pathogen coerces the development of plants to influence the behaviour of its insect vector, maximizing the transmission of AY-WB to new hosts. 
Cucumber mosaic virus-induced changes in volatile production and plant quality: Implications for disease transmission and multitrophic interactions K. MAUCK (1), C. De Moraes (1), M. Mescher (1)

(1) ETH Zurich, Zurich, Switzerland

Phytopathology 104(Suppl. 3):S3.151

Virus infection may indirectly modify interactions between plants and the broader insect community through effects on host phenotype, with significant implications for virus fitness. To understand these effects, we explored the influence of infection by Cucumber mosaic virus (CMV) on interactions among Cucurbita pepo, aphid vectors of CMV, aphid natural enemies, and non-vector herbivores. Our results show that infection of $C$. pepo by CMV stimulates plants to produce higher amounts of constitutive volatiles normally released by healthy $C$. pepo, but that infection also reduces plant quality, stimulating rapid vector dispersal after acquisition of taste cues and virions. This behavior is the result of several biochemical changes that are induced in CMV-infected C. pepo, and which decrease host palatability and quality. These changes can also have significant implications for aphid interactions with natural enemies, as we found that aphids reared on CMV-infected plants are more susceptible to parasitoid attack. While these natural enemies benefit from virus infection, field experiments show that $\mathrm{CMV}$-infected $C$. pepo are largely avoided by various non-vector herbivores. Overall, our results indicate that infection by a non-persistently transmitted virus can have significant, indirect, impacts on various trophic levels, and that selection may act on viruses to favor traits that alter host phenotypes if such changes result in increased transmission.

Interconnected Lifecycles: Multitrophic interactions between plants, pathogens, and insects

D. ROTENBERG (1)

(1) Kansas State University, Dept. Plant Pathology, Manhattan, KS, U.S.A.

Phytopathology 104(Suppl. 3):S3.151

A diverse array of pathogens are transmitted to plants by insect vectors. Many of the pathogens that impact agricultural and natural ecosystems are associated with insects, increasing the need to understand the myriad relationships between these biotic stressors and their shared plant hosts. Teasing apart these relationships has revealed both direct and indirect effects of the pathogen on the vector. For example, infection of a plant can result in differential attraction to and dispersal from plants and can have significant effects on insect performance. In turn, the pathogen is reliant on the vector for dispersal to and establishment on the plant host. Plant nutritional quality and volatiles have been identified as chemical factors associated with indirect effects on insect vectors. Recently, the application of systems-level approaches has enabled dissection of the interactions of the partners at the molecular level and an emerging theme is that host defense response modulates the interactions between vector and pathogen. Additionally, ecological-level research is advancing rapidly due to improved technologies for chemical ecology and epidemiological studies at the plant, field, and landscape level. This symposium highlights some of the most important viral and bacterial pathosystems at the ecological and molecular-levels and will identify new research fronts to advance the field.
Across the spectrum: Effects of virus infections on host preference and fitness of vectors

R. SRINIVASAN (1)

(1) University of Georgia, Tifton, GA, U.S.A.

Phytopathology 104(Suppl. 3):S3.151

Phytoviral infections often alter the physiological and phenotypic traits of hosts. Such alterations are known to differentially modulate host preference and fitness of vectors. The variations in vector responses seem to be influenced by the intricacy of interactions between the vector and the virus. The spectrum of virus transmission by vectors stretches from non-persistent and non-circulative mode to persistent, circulative, and propagative mode. In all scenarios, the interactions between the vector and the virus seem to favor pathogen dispersal with little to significant fitness benefits to vectors. For instance, alterations in hosts induced by non-persistent viruses seem to deceptively attract the vectors but offer little or no fitness benefits to vectors, ultimately favoring acquisition and inoculation of viruses. On the contrary, evidence indicates that persistent viruses make the plants more apparent to their vectors and positively influence vector fitness, ultimately favoring virus acquisition and inoculation. At the other end of the spectrum, persistent propagative viruses seem to manipulate their vectors' fitness in a bidirectional fashion, ultimately also benefitting virus transmission. In some cases, however, the effects of viruses on their vectors seem to be independent of changes in host traits. Nevertheless, in all scenarios, "clever viruses" by manipulating their vectors seem to aid their own dispersal.

Insect vectors are attracted to sub-optimal pathogen-infected plants; Can environment be manipulated to prevent vectors from finding infected trees?

L. L. STELINSKI (1)

(1) University of Florida, Lake Alfred, FL, U.S.A.

Phytopathology 104(Suppl. 3):S3.151

We demonstrate specific mechanisms through which a bacterial plant pathogen induces plant responses that modify behavior of its insect vector. Candidatus Liberibacter asiaticus, a fastidious, phloem-limited bacterium responsible for causing huanglongbing disease of citrus, induced release of a specific volatile chemical, methyl salicylate, which increased attractiveness of infected plants to its insect vector, Diaphorina citri, and caused vectors to initially prefer infected plants. However, the insect vectors subsequently dispersed to non-infected plants as their preferred location of prolonged settling because of likely sub-optimal nutritional content of infected plants. The duration of initial feeding on infected plants was sufficiently long for the vectors to acquire the pathogen before they dispersed to non-infected plants, suggesting that the bacterial pathogen manipulates behavior of its insect vector to promote its own proliferation. We are currently exploring whether masking the environment with large amounts of methyl salycilate may prevent vectors from homing in on bacterially infected trees analogously to the mating disruption technique. Preliminary evidence suggests that we may be able to reduce the vector's ability to discriminate between infected and uninfected trees, potentially reducing pathogen spread.

\section{Molecular/Cellular/Plant-Microbe Interactions}

\section{Potyviruses: Functional Genomics and Virus-Host Interactions}

\author{
Interactions of HCpro and VPg of Potato virus A with eIF4E \\ M. Ala-Poikela (1), M. L. Rajamäki (1), J. P. VALKONEN (1) \\ (1) University of Helsinki, Helsinki, Finland \\ Phytopathology 104(Suppl. 3):S3.151
}

Potyviruses (genus Potyvirus; family Potyviridae) cause yield losses in a wide range of crop plants. Host proteins that are central to potyvirus infection include the eukaryotic translation initiation factor eIF4E and the isoform eIF(iso)4E. A viral genome-linked protein ( $\mathrm{VPg}$ ) is covalently bound to the 5 , end of the $(+)$ ssRNA genome of potyviruses and interacts with eIF4E and eIF(iso)4E via the $\mathrm{m} 7 \mathrm{G}$ cap-binding pocket. The most straightforward hypothesis is that VPg imitates the cap to support viral translation and/or inhibit host translation by binding to eIF4E/iso4E. Our results show that also the HCpro protein of potyviruses interacts with eIF4E/iso4E, which occurs via the 4E-binding motif YXXXXL $\Phi$ of HCpro that is similar to the motif in scaffold protein eIF4G. Thus, also HCpro may inhibit cap-dependent translation by preventing 4E from binding to eIF4G. Furthermore, the 4E- binding motif YXXXXL $\Phi$ was recognized in the VPg of Potato virus A and two other potyviruses. Substitution of the conserved residues in the 4Ebinding motif of VPg abolished or weakened the interaction of VPg with eIF4E/iso4E in planta and abolished infectivity of PVA in plants. Hence VPg can interact with two domains of eIF4E/iso4E via two independent motifs. Taken together, the results suggest novel mechanisms by which potyviruses interact with the host translation system and other putative functions involving eIF4E/iso4E

Interactions of Soybean mosaic virus with resistant soybean genotypes: Virulence determinants and practical implications

R. HAJIMORAD (1)

(1) The University of Tennessee, Dept. of Entomology \& Plant Pathology, Knoxville, TN, U.S.A.

Phytopathology 104(Suppl. 3):S3.151

Plants have evolved resistance $(R)$ genes to defend against invading pathogens. Deployment of $R$ genes is considered as the most effective, economically sound and environmentally friendly approach to control viral diseases of plants. However, durability of $R$-genes remains a matter of 
concern. $R$ gene-mediated resistance operates based on 'gene-for-gene' hypothesis, where a specific $\mathrm{R}$ protein recognizes, directly or indirectly, a specific pathogen protein, termed an 'avirulence factor'. To gain virulence, plant viruses alter avirulence proteins by one or more amino acid substitutions. However, viral proteins are multifunctional and gain of virulence mutations may have negative impact on fitness. In spite of the economic importance of potyviruses, studies on potyviral avirulence/virulence determinants involving $R$-genotype plants are limited. Soybean mosaic virus (SMV) and soybean genotypes containing $R$ genes have been used as a model potyviral pathosystem to define avirulence/virulence determinants of SMV using various approaches. Traditionally, durability of $R$-genes is determined upon long deployment under pathogen pressure; however, avirulence/ virulence determinants may serve as reliable predictors of durability of $R$ genes. Current knowledge on virulence determinants of SMV on resistant soybeans will be discussed in relation to strategies for durable deployment of $R$-genes.

Interactions of Bean common mosaic virus with resistance genes in common beans

A. V. KARASEV (1), X. Feng (1), A. R. Poplawsky (1)

(1) University of Idaho, Moscow, ID, U.S.A.

Phytopathology 104(Suppl. 3):S3.152

Bean common mosaic virus (BCMV) is a potyvirus affecting common bean (Phaseolus vulgaris L.). BCMV exists as a complex of strains that are differentiated based on interactions with virus resistance genes identified in beans. However, genetic diversity of BCMV strains have not yet been fully appreciated, and genetic determinants responsible for interactions of BCMV strains with resistance genes have not yet been identified. In common beans, resistance to BCMV is governed by seven genes, one dominant $I$ gene, and six recessive genes, $b c-u, b c-1, b c-1^{2}, b c-2, b c-2^{2}$, and $b c-3$. Consequently, seven BCMV pathotypes are identified, numbered from I to VII, depending on the pattern of interactions with differential bean lines carrying various combinations of resistance genes. A systematic screening was conducted focused on BCMV strains from different pathotypes and identification of genetic determinants involved in interactions with the $I$ gene, and two recessive genes, $b c-2$, and $b c-2^{2}$. Upon sequencing whole genomes for four BCMV isolates exhibiting pathotypes VI and VII and interacting with $b c-2$ and $b c-2^{2}$ genes, and one isolate exhibiting pathotype VII and inducing temperature-insensitive necrosis in an $I$-bearing bean line, these genetic determinants were tentatively mapped to the P1-HC-Pro region of BCMV. It appears that recombination between BCMV genomes may be quite common, and BCMV strains often represent multiple recombinants.

Multiple roles of Wheat streak mosaic virus coat protein in virus biology S. TATINENI (1), A. J. McMechan (2), G. Hein (2)

(1) USDA-ARS, Lincoln, NE, U.S.A.; (2) University of Nebraska-Lincoln, Lincoln, NE, U.S.A.

Phytopathology 104(Suppl. 3):S3.152
Wheat streak mosaic virus (WSMV) is an economically important member of the Potyviridae family impacting wheat production in the Great Plains region. The role of WSMV coat protein $(\mathrm{CP})$ in virus biology was examined by introducing a series of point or deletion mutations into the $\mathrm{CP}$ cistron, and it was found that WSMV is unusually tolerant of extensive CP deletions. The Nterminal amino acids (aa) 6 to 27 and 85 to 100 are required for efficient virion assembly and cell-to-cell movement, while the C-terminal 65 aa are dispensable for virion assembly but required for cell-to-cell movement. This suggests that the $\mathrm{C}$-terminus of $\mathrm{CP}$ functions as a dedicated determinant for cell-to-cell movement. In contrast, aa 36 to 84 are expendable for virion assembly and systemic infection, and deletion of aa 58 to 84 induced more severe symptoms than the wild-type virus, suggesting that $\mathrm{CP}$ functions as a suppressor of virulence. Moreover, efficient systemic infection by WSMV mutants with precise exchange of aa between 36 and 84 with nonviral aa could facilitate expression and display of specialty peptides/epitopes embedded into virions. Furthermore, aa 58 to 100 are required for transmission by the wheat curl mites; however, aa 6 to 27,36 to 57 and the C-terminal 14 aa are dispensable for mite transmission. Our studies revealed that WSMV CP possesses distinct functional domains involved in virion assembly, virus movement, host range, suppression of virulence, and mite transmission.

Molecular understanding of potyvirus infection processes for the development of novel antiviral strategies

A. WANG (1)

(1) Agriculture \& Agri-Food Canada, London, ON, Canada

Phytopathology 104(Suppl. 3):S3.152

Potyviruses represent the largest group of known plant viruses, which includes many agriculturally important viruses. Genetic resistance proves to be the most effective means to control viral diseases. Unfortunately, resistant resources in nature are very rare. The development of novel antiviral strategies requires a better understanding of the complex molecular interplay between the host plant and the invading virus. In the past decade, my laboratory has been focused on elucidating plant-potyvirus interactions, potyviral replication mechanisms and potyviral cell-to-cell movement, identifying host factor genes required for potyviral infection, and developing novel germplasms resistant to potyviruses. Our studies have demonstrated that potyviral replication vesicles originate from the ER and translocate to chloroplasts for robust genome replication. The potyviral cell-to-cell movement is mediated by the recently found viral protein P3N-PIPO via its interaction with the potyviral cyclindrical inclusion $(\mathrm{CI})$ protein to form conical structures at plasmodesmata (PD). Several host factor genes have been identified that are essential for potyviral accumulation. In addition, we have also engineered genetic resistance into the natural host of some potyviruses through the hairpinmediated RNA silencing (RNAi) approach. Currently, we are generating mutant populations of several crop species and screening for specific gene mutants resistant to target potyviruses.

\section{Revealing the Stories of the Genome Via Genotyping-By-Sequencing (GBS)}

\author{
Application of Genotyping-by-Sequencing for mapping disease resistance \\ in grapevine breeding families \\ L. CADLE-DAVIDSON (1), P. Barba (2), Q. Sun (3), K. Hyma (3), E. Takacs \\ (2), J. Lillis (1), C. Ledbetter (4), D. Ramming (4), B. Reisch (2) \\ (1) USDA-ARS Grape Genetics Research Unit, Geneva, NY, U.S.A.; (2) \\ Cornell University, Geneva, NY, U.S.A.; (3) Cornell University, Ithaca, NY, \\ U.S.A.; (4) USDA-ARS, Parlier, CA, U.S.A. \\ Phytopathology 104(Suppl. 3):S3.152
}

Genotyping-by-Sequencing (GBS) is a low-cost, high-throughput method for genome-wide polymorphism discovery and genotyping adjacent to restriction sites. Since 2010, GBS has been applied for the genotyping of over 12,000 grape breeding lines, with a primary focus on identifying markers predictive of disease resistance. Using standard SNP calling pipelines in TASSEL with the Vitis vinifera 'PN40024' reference genome, 20,000 to 50,000 SNPs per family remain after moderately stringent filtering based on genotype quality, allele frequency, and missing data. For linkage mapping, more stringent filters are applied to obtain about 5,000 robust markers, which is sufficient for typical population sizes in grape breeding programs. Qualitative marker-trait associations were identified for resistance to foliar powdery mildew or to Phomopsis cankers on canes. In addition, a quantitative locus underlying powdery mildew susceptibility from $V$. vinifera 'Chardonnay' was identified
(Sen1), explaining about $22 \%$ of the variation in disease severity. Because disease resistance is often an introgressed trait from wild Vitis into domesticated $V$. vinifera genetic backgrounds, GBS provides the opportunity to select for resistance loci (and/or against susceptibility) simultaneous to genome-wide selection for $V$. vinifera alleles to accelerate trait introgression.

Genetic basis of quantitative virulence and the impact of recombination hotspots in Zymoseptoria tritici identified by high-throughput RADsequencing

D. CROLL (1), E. Stewart (1), B. A. McDonald (1)

(1) ETH Zurich, Zurich, Switzerland

Phytopathology 104(Suppl. 3):S3.152

Zymoseptoria tritici (formerly Mycosphaerella graminicola) is a heterothallic ascomycete causing wheat septoria tritici leaf blotch. The deployment of resistant wheat cultivars is complicated by the high diversity within populations. Sexual reproduction is frequent and contributes significantly to the high evolutionary potential of $Z$. tritici. We aimed to understand two fundamental properties of $Z$. tritici. What is the genetic basis of quantitative virulence of $Z$. tritici on wheat? How does recombination shape the evolutionary trajectory of the pathogen genome? For this, we adapted the high-throughput genotyping method based on restriction-associated DNA sequencing (RADseq). We genotyped a total of 441 progeny from two sexual crosses at over $23^{\prime} 000$ SNP loci in order to generate a highly saturated genetic map. We successfully mapped QTLs underlying leaf necrosis and pycnidial densities for two different wheat cultivars. The genetic architecture of 
virulence on wheat is likely complex as QTL regions differed between the progeny populations. We found that recombination rates were highly heterogeneous along chromosomes. Recombination hotspots were preferentially located in subtelomeric regions. We found that recombination hotspots are linked to the population genomic diversity of the pathogen. The evolutionary potential of virulence genes is, hence, likely influenced by local variations in recombination rates

Exploring the use of genotyping-by-sequencing to characterize the forest epidemic of Phytophthora ramorum in Oregon

S. E. EVERHART (1), B. J. Knaus (2), A. Kanaskie (3), W. Sutton (1), P. Reeser (1), A. L. Dale (4), R. C. Hamelin (4), E. Hansen (1), N. J. Grunwald (5)

(1) Oregon State University, Corvallis, OR, U.S.A.; (2) US Department of Agriculture-Agricultural Research Service, Horticultural Crop Research Unit, Corvallis, OR, U.S.A.; (3) Oregon Department of Forestry, Salem, OR, U.S.A.; (4) University of British Columbia, Vancouver, BC, Canada; (5) Oregon State University, Department of Botany and Plant Pathology, US Department of Agriculture-Agricultural Research Service, Horticultural Crop Research Unit, Corvallis, OR, U.S.A.

Phytopathology 104(Suppl. 3):S3.153

Clonal, emerging plant pathogens pose a serious challenge for traditional population genetic approaches. For Phytophthora ramorum, previous work using microsatellite markers examining the forest outbreak in Oregon revealed little genotypic variation within the NA1 lineage, where almost half of 1,589 isolates shared the same multilocus genotype. Inability to detect variation makes it difficult to answer questions regarding epidemic spread. Thus, the goal of our work was to explore genotyping-by-sequencing (GBS) as a new approach to re-examine the $P$. ramorum disease outbreak in Oregon. Specifically, our first objective was to determine if GBS yields sufficient variants as compared to whole-genome sequencing (WGS). To facilitate validation, we performed GBS on the same isolate used for generation of the $P$. ramorum reference genome. Preliminary results were generated for the longest scaffold (1.24 Mbp) in the reference genome. GBS data for the reference isolate showed there was only one discordant variant (homozygous for the alternate allele), representing $0.109 \%$ of SNPs. Comparing GBS data for 3 NA1 isolates to WGS data for 3 NA1 isolates, GBS yielded 0.731 SNPs per $\mathrm{Kbp}$, which is equivalent to $38.3 \%$ of SNPs discovered via WGS, where $48.6 \%$ had a SNP call at the same position. Currently underway is application of this approach to characterize the disease dynamics of $P$. ramorum outbreak from 2001 to the present, focusing on the front of the epidemic.

\section{The use of GBS to improve genome assembly}

J. GLAUBITZ (1), F. Lu (1), E. Buckler (2)

(1) Institute for Genomic Diversity, Cornell University, Ithaca, NY, U.S.A.; (2) USDA-ARS; Institute for Genomic Diversity, Cornell University, Ithaca, NY, U.S.A.

Phytopathology 104(Suppl. 3):S3.153

Genotyping by sequencing (GBS) is a reduced representation, next generation sequencing approach that provides a robust and cost-effective means to genotype large numbers of individuals at high density, by targeting sequence adjacent to restriction enzyme cut sites. The robustness and cost-effectiveness of the GBS protocol derives from its relative simplicity. To date, we have genotyped more than 50,000 maize samples via GBS and have constructed our own bioinformatics pipeline for the analysis of this large, but relatively sparse, data set. One potential application of GBS data is to improve the reference genome of a species, either by following the genetic segregation of GBS sequence tags in biparental linkage mapping populations or by LD mapping of the tags in the full set of unrelated individuals genotyped. Such genetic mapping data can be used to (1) examine how representative the reference genome is for other individuals in the species, particulary in light of the abundant structural variation known to occur in many plant species, (2) correct contig placement errors in the reference genome, (3) assign previously unanchored contigs or de novo contigs to a chromosomal region, and (4) provide a genetic framework map to aid construction of a pan-genome across multiple individuals. This presentation will update our progress in maize in relation to all four of these objectives.

Genotyping-by-Sequencing sheds new light on the biology of Verticillium dahliae

M. JIMENEZ-GASCO (1), M. G. Milgroom (2), C. Olivares-Garcia (3), R. M. Jimenez-Diaz (3)

(1) The Pennsylvania State University, University Park, PA, U.S.A.; (2) Cornell University, Ithaca, NY, U.S.A.; (3) University of Cordoba, and Institute for Sustainable Agriculture, CSIC, Cordoba, Spain

Phytopathology 104(Suppl. 3):S3.153

Verticillium dahliae is a plant-pathogenic, ascomycete fungus with no known sexual stage and a highly clonal population structure. Populations of this pathogen have been traditionally studied by means of vegetative compatibility groups (VCGs) that correlate with clonal lineages. However, discrepancies in phylogenetic relationships among those clonal lineages have been found that may be explained by recombination. Genotyping by sequencing was conducted on $141 \mathrm{~V}$. dahliae isolates representative of host, geographic origin, pathotype, and VCG. We genotyped 26,748 SNPs and detected 443 unique recombination events evenly distributed throughout the genome. Evidence of recombination was widespread among clonal lineages, with few recombinant haplotypes detected within clonal lineages. The extent and patterns of recombination observed suggest that clonal lineages arose by sexual reproduction. We also studied the phylogeography of $V$. dahliae defoliating pathotype (D), currently widespread and associated with olive cultivation. SNP haplotype networks and coalescent analysis showed that the D pathotype originated from USA and has been independently introduced five times into the Mediterranean region. We hypothesize that the current clonal population structure in $V$. dahliae has arisen as a consequence of selection due to agriculture. This research indicates that recombination can potentially give rise to new clonal lineages and thereby increase genotypic diversity.

RADseq: A population genomics tool to study the genetic diversity of Exobasidium sp., an emerging blueberry pathogen

J. E. STEWART (1), T. Glenn (1), M. T. Brewer (1)

(1) University of Georgia, Athens, GA, U.S.A.

Phytopathology 104(Suppl. 3):S3.153

Exobasidium leaf and fruit spot of blueberry is an emerging disease that has rapidly increased in incidence throughout Georgia and the southeastern USA causing significant losses in some fields. Recent research, based on morphological and phylogenetic analyses, demonstrated that this disease in the Southeast is caused by a previously undescribed species, Exobasidium maculosum. Our current research utilizes direct sequencing of three genomic regions, the internal transcribed spacer region of the rDNA, elongation factor1 alpha and beta-tubulin, and restriction site associated DNA markers (RADseq) to estimate the genetic diversity of E. maculosum within the southeastern USA and between a closely-related species, Exobasidium sp. A found on lowbush blueberry in the northeastern USA and Canada. A total of 691 SNPs among 189 loci were found between E. maculosum and Exobasidium sp. A. This provides additional support for the existence of two unique species causing leaf and fruit spot on, E. maculosum on rabbiteye, highbush and southern highbush blueberry in the Southeast and Exobasidium sp. A on lowbush blueberry in the Northeast. Populations of E. maculosum collected from Georgia and North Carolina are highly diverse and appear to be one large population based on the presence of recombination and a lack of genetic structuring in geographically diverse populations. Possible mechanisms driving the genetic diversity observed in E. maculosum will be discussed.

\section{The Complicated Lifestyles of Dothideomycete Fungi: Understanding Novel Mechanisms of Pathogenicity}

\section{Molecular dissection of stomatal infection in Cercospora zeae-maydis \\ B. BLUHM (1) \\ (1) University of Arkansas, Fayetteville, AR, U.S.A. \\ Phytopathology 104(Suppl. 3):S3.153}

Cercospora zeae-maydis causes gray leaf spot, a ubiquitous and potentially devastating disease of maize. During pathogenesis, C. zeae-maydis senses and grows towards host stomata, followed by a latent, hemi-biotrophic phase preceding the induction of necrosis. To understand the molecular basis of infection in C. zeae-maydis, we employed a combination of techniques in molecular genetics and functional genomics. Recently, we established a genetic linkage between light sensing, the circadian clock of C. zeae-maydis, and stomatal perception. Additionally, we identified putative regulators of stomatal infection through a forward genetic screen combined with differential expression profiling via RNA-seq. Furthermore, we are utilizing comparative genomics to identify putative regulators of pathogenesis in $C$. zeae-maydis. To this end, we recently obtained draft genome sequences for $C$. zeina (a sibling species of C. zeae-maydis that also causes gray leaf spot of 
maize), C. sojina (causes frogeye leaf spot of soybean), and C. kikuchii (causes Cercospora leaf blight of soybean). Of particular interest are genes undergoing diversifying selection, displaying interesting presence/absence patterns, or are unique at the genus or species level. Although many questions remain to be answered, findings to date have increased the understanding of stomatal infection and led to the formulation of new hypotheses regarding pathogenesis in C. zeae-maydis.

Cercospora kikuchii: Detection and identification of key virulence proteins

A. K. CHANDA (1), Z. Y. Chen (1), R. W. Schneider (1)

(1) Louisiana State University AgCenter, Baton Rouge, LA, U.S.A.

Phytopathology 104(Suppl. 3):S3.154

Cercospora kikuchii is the causal agent of Cercospora leaf blight (CLB) of soybean. Typical symptoms of CLB appear only at the seed-filling stage (R5), and early detection is essential for effectively managing this disease. We developed a TaqMan probe-based qPCR assay for detection of C. kikuchii in naturally infected soybean leaves. We documented a very long latent infection period for this pathogen in soybean before the appearance of visible symptoms. We also used this qPCR assay to evaluate the efficacy of fungicides commonly used for managing CLB by quantifying DNA of $C$. kikuchii in leaves collected during various growth stages. Our results showed that multiple fungicide applications beginning at flowering (R1) suppressed the development of $C$. kikuchii in leaves. In addition, to better understand the relationship between the production of cercosporin, a light-regulated polyketide toxin, and the virulence of the pathogen, we used two dimensional gel-based proteomics approach to identify differentially expressed proteins by comparing light- and dark-grown cultures of the pathogen. Six proteins were up-regulated and two were down-regulated in $C$. kikuchii grown under light. Two of the up-regulated proteins [hydroxynaphthalene reductase $(H N R)$ and adenosylhomocysteinase $(A H C Y)]$ were further studied through gene disruption. The resulting mutants produced less cercosporin in vitro and they were less virulent on soybean leaves.

Dothideomycete plant pathogens require specific virulence factors for colonization and host plants have developed specific $\boldsymbol{R}$ genes for defence P. J. DE WIT (1), C. Mesarich (1), B. Okmen (1), A. van der Burgt (1), Y. Iida (1), E. Battaglia (1), H. Beenen (1), S. Griffiths (1), J. Collemare (1), R. E. Bradshaw (2)

(1) Wageningen University, Wageningen, Netherlands; (2) Massey University, Palmerston North, New Zealand

Phytopathology 104(Suppl. 3):S3.154

The tomato pathogen Cladosporium fulvum is a Dothideomycete that is most related to the hemi-biotrophic fungal pine pathogen Dothistroma septosporum. We study genomic adaptations in these and related fungi that can explain host plant-specificity. The C. fulvum genomic sequence allowed us to identify and study its complete effector catalogue including three core effectors (Avr4, Ecp2 and Ecp6). The genome of D. septosporum harbors the highest number of homologs of C. fulvum effectors, but some are pseudogenized. Both C. fulvum and D. septosporum contain a large number of genes involved in the production of secondary metabolites. C. fulvum seems to adapt its host plant tomato by down-regulation or pseudogenization of genes involved in the production of toxic secondary metabolites. One example is dothiostromin, a toxin produced by $D$. septosporum during colonization of pine needle. C. fulvum contains all genes required for the production of this toxin, but a few of these genes are pseudogenized. Apart from new effectors (Avr5) we have also identified new pathogen-associated molecular patterns (PAMPs) and damage-associated molecular patterns (DAMPs) from $C$. fulvum. Both represent cell-wall degrading enzymes produced by $C$. fulvum during infection of tomato. We also found that C. fulvum has adapted to grow on tomato by secreting the enzyme $\alpha$-tomatinase that hydrolyses the antifungal tomato saponin $\alpha$-tomatine into the non-toxic compounds lycotetraose and tomatidine.

Investigations of how the necrotrophic specialist Parastagonospora nodorum is using the dual function necrotrophic effector SnTox1 to infect wheat

T. L. FRIESEN (1), Z. Liu (2), Y. M. Kim (2), Y. Gao (2), P. J. De Wit (3), J. D. Faris (1)

(1) USDA-ARS Northern Crop Science Laboratory, Cereal Crops Research Unit, Fargo, ND, U.S.A.; (2) North Dakota State University, Fargo, ND, U.S.A.; (3) Wageningen University, Wageningen, Netherlands

Phytopathology 104(Suppl. 3):S3.154

Parastagonospora nodorum (Synonym Stagonospora nodorum) is a destructive pathogen of wheat that induces yield and quality losses by causing disease on both the leaves and glumes of wheat. $P$. nodorum is a necrotrophic specialist pathogen that secretes an arsenal of necrotrophic effectors (NEs) involved in disease induction. SnTox1 was the first of seven NEs reported from $P$. nodorum and was shown to interact directly or indirectly with the single dominant susceptibility gene Snn1. The SnTox1-Snn1 interaction induces several hallmarks of a defense response including an oxidative burst and DNA laddering, a classic apoptosis response, but results in susceptibility rather than resistance. Although several necrotrophic specialists are known to induce the defense response while causing disease, little is known about how necrotrophic specialists survive the harsh environment of the host defense response. SnTox1 contains homology to several plant chitin binding proteins and we have shown that SnTox1 localizes to the cell wall of mycelium in culture and that SnTox1 binds purified chitin. We have cloned and expressed several wheat chitinases and used them to show that SnTox 1 not only induces PCD but that SnTox1 also has a second role of binding chitin in the fungal cell wall, resulting in protection from these wheat chitinases. The dual function of this protein explains the high prevalence of SnToxl, relative to other NEs in the P. nodorum global population.

The stealth pathogenicity of Mycosphaerella graminicola (aka Zymoseptoria tritici)

S. B. GOODWIN (1)

(1) USDA-ARS / Purdue University, West Lafayette, IN, U.S.A.

Phytopathology 104(Suppl. 3):S3.154

Mycosphaerella graminicola (synonym: Zymoseptoria tritici; anamorph: Septoria tritici) causes Septoria tritici blotch (STB) of wheat. STB is an economically important disease that occurs throughout the world wherever wheat is grown. The pathogen typically infects through stomata, colonizes the substomatal cavity and then grows intercellularly for 8-12 days during a biotrophic phase before causing massive cell death and necrosis and then switching to necrotrophic growth. Its exact mode of nutrition during biotrophic growth, what triggers the switch from biotrophy to necrotrophy and which genes are expressed during necrotrophic growth are not known. To better understand these processes, the genome of the pathogen was sequenced completely by the Joint Genome Institute of the U.S. DOE. The $39.7-\mathrm{Mb}$ genome consists of 21 chromosomes, 8 of which can be lost with no obvious phenotypic effects so are dispensable and probably were acquired during the past 10,000 years. The genome contained a reduced number of genes for cell wall-degrading enzymes compared to other plant pathogens and many of those that are present are not expressed during the biotrophic phase of infection, leading to the hypothesis that protein degradation may be more important than carbohydrates for biotrophic growth. The reduced number of genes for cell wall-degrading enzymes and lowered expression during biotrophic growth may be an adaptation to facilitate the stealth pathogenicity of $M$. graminicola.

\section{Understanding Phytobiomes to Improve Agricultural Productivity}

How do agricultural practices impact the animal microbiome?

H. K. Allen (1), T. STANTON (1)

(1) USDA/ARS/National Animal Disease Center, Ames, IA, U.S.A. Phytopathology 104(Suppl. 3):S3.154

The swine gastrointestinal tract is a rich environment containing up to 1000 different species of commensal bacteria. This collection of gut bacteria, or gut microbiota, confers benefits to the host under normal conditions. Disturbance of the gut microbiota is one collateral effect of in-feed antibiotics, which have many uses in animal agriculture (disease treatment or prevention and feed efficiency improvement). We are interested in defining the swine gut microbiota and how it is affected by antibiotics to inform alternatives to growth-promoting antibiotics. To this end, we studied the impacts of ASP250 (chlortetracycline, sulfamethazine, and penicillin) on the microbiota over time and at different intestinal locations. The microbiota was analyzed for its bacterial members (via the 16S rRNA gene) and functions (via metagenomics). The results show that the gut microbiota is functionally adapted to discrete intestinal locations. For example, the large intestinal microbiota encoded a large number of genes to degrade plant cell wall components, and these genes were lacking in the ileum microbiota. Additionally, the microbiota of antibiotic-fed animals diverged from that of control animals, with notable changes being increases in E. coli populations and in resistance genes to antibiotics not administered. Characterizing the gut 
microbiome in health and in antibiotic-mediated disturbances will inform strategies to improve swine health and food safety.

Phytobiome, a new view of crop production - an industry perspective M. GUILHABERT-GOYA (1)

(1) Bayer CropScience LP, Davis, CA, U.S.A

Phytopathology 104(Suppl. 3):S3.155

The study of plant-microbe associations by new techniques has significantly improved our understanding of the structure and specificity of the plant microbiome. Comparable with our human microbiome, millions of microbes inhabit plants, forming complex ecological communities that influence plant growth and health through its collective natural product chemistry activities and host interactions. Work has shown that natural chemical signals from the root-colonizing bacteria trigger physiological changes in their host plants, leading to increased growth and yields. Biologics, Bayer Crop Science believes however that we are only now scratching the surface of developing microbiological products which can increase agriculture production using integrated solutions. Studying the root phytobiome in a field ecosystem can provide insight into how to promote plant health and stress tolerance of their hosts or how to adapt to various environmental conditions by manipulating this microbial community. Furthermore, improving genomic tracking techniques and diagnostics has the potential to characterize and enhance microbes benefiting the growing crops. For example, VOTiVO (Bacillus firmus), a microbial seed treatment, added on corn, in 2007 and 2008 an extra 4-5 bushels on top of the yield increase from Poncho. In multiple soybean trials, VOTiVO added an average 1.5 bushels per acre on top of the yield benefits of Trilex 6000

Separating signal from noise in the design and analysis of host-microbial communities

E. W. TRIPLETT (1)

(1) University of Florida, Gainesville, FL, U.S.A.

Phytopathology 104(Suppl. 3):S3.155

Culture-independent analyses of host-microbial communities can be used in lieu of Koch's postulates for an uncultured pathogen as we have done for citrus greening disease. Prior to our work on this subject, there was strong evidence that the causal agent of citrus greening disease was a phloemlimited, uncultured alphaproteobacterium, $\mathrm{Ca}$. Liberibacter asiaticus (CLas). The vast majority of plants with symptoms were PCR-positive for CLas. However, as this organism has not been cultured, Koch's postulates have never been performed. There were some suggestions that disease may be caused by other bacteria or bacteria in combination with CLas. Subsequent metagenomic analysis of infected phloem tissue showed that the only bacterium present in citrus phloem was CLas. Where a causal agent is not known, careful experimental design can identify an organism strongly associated with disease. In addition, the associated organism may not be the exclusive causal agent of disease. That is, a set of bacterial functions commonly shared by several taxa may cause disease. In human, animal, or plant microbiome research, it is important to keep in mind the many environmental factors that confound the results. We propose that the number of environmental confounders associated with disease be minimized in experimental design. Examples will be presented where culture independent analyses identified organisms correlated with the presence of disease and land use.

How do organisms communicate (cross-kingdom communications) in the phytobiome?

V. VENTURI (1)

(1) International Centre for Genetic Engineering and Biotechnology, Trieste, Italy

Phytopathology 104(Suppl. 3):S3.155

Just like what occurs in humans, plants have been recently recognized as meta-organisms possessing a distinct microbiome which has close relationship with their associated microoganisms. The plant microbiome presents an additional reservoir of genes that the plant can have access to when needed. Plant health is thought to heavily depend also on its microbiome and plants most probably intimately affect bacterial gene expression via a communication highway of signals produced by bacteria and plants. These complex highways will become clearer through the detection of signal molecules and identifying the effects on gene expression of microbial and plant exudates. Although plant microbiome composition is now being well studied, there is hardly any information on these signals. This communication, also called interkingdom signaling, is now a fast developing field of research. It has really only been studied in some depth in rhizobial-legume associations and pathogenesis between agrobacteria and host plants. We have identified a new sub-family of LuxR proteins which is widely present in plant associated proteobacteria which binds and consequently responds to plant signals. This study reveals a novel and widespread interkingdom circuit widely present in bacterial members of core microbiomes indicating that plants can influence their microbiota. Understanding these types of communication between microbiomes and plants are a step in the right direction for disease management.

The phyllosphere microbiome: Responses to and impacts on plants J. A. VORHOLT (1)

(1) ETH Zurich, Zurich, Switzerland

Phytopathology 104(Suppl. 3):S3.155

Plants are colonized by a variety of microorganisms, including bacteria, fungi and yeasts. In the above-ground part of plants, known as the phyllosphere, bacteria are the most abundant inhabitants. The importance of the phyllosphere microbiota for resistance against phytopathogenic bacteria or fungi is not yet well understood. Members of the genus Sphingomonas constitute a significant fraction of up to $20 \%$ of the phyllosphere population of healthy plants making them prime candidates to investigate in how far indigenous phyllosphere bacteria have the ability to protect the plant against pathogens. Recently, we have shown that various Sphingomonas strains such as Sphingomonas sp. Fr1 protect Arabidopsis against the bacterial pathogen Pseudomonas syringae DC3000 in a gnotobiotic model system. A number of complementary experiments will be presented including a bacterial forward genetic in planta screen and plant transcriptome analyses aiming at elucidating the mode of action of indigenous phyllosphere bacteria in plant protection. Vorholt JA (2012) Microbial life in the phyllosphere. Nature Rev. Microbiol. $10: 828-840$.

\section{Professionalism/Outreach}

\section{Beyond Borlaug: How the Next Generation of Plant Pathologists are Advancing the Green Revolution}

\author{
Agricultural Science Capacity Building in Afghanistan: Reading Agrios \\ in Kabul \\ T. C. CRESWELL (1) \\ (1) Purdue University, West Lafayette, IN, U.S.A. \\ Phytopathology 104(Suppl. 3):S3.155
}

Education in the plant sciences in Afghanistan has suffered greatly from the departure of trained faculty and experienced agriculturalists and by damage to infrastructure during prolonged wars, beginning with the Soviet invasion in 1979. By the time NATO took over security in Kabul in 2003 the entire higher education system in Afghanistan was approaching collapse. The international community has been helping rebuild since 2002, pledging more than $\$ 21$ billion in 2008 to help the country develop infrastructure and institutions.
Purdue University, with support from USAID and USDA has been actively engaged in capacity building for higher education agriculture colleges, the Ministry of Agriculture and the Ministry of Public Health. This session will cover efforts to promote the study of plant pathology, build an extension system and provide training in plant problem diagnostic skills in Afghanistan in the agriculture colleges and in the Ministry of Agriculture's Plant Protection and Quality Department.

Mountains beyond mountains: Challenges and opportunities for managing peanut diseases in Haiti

A. M. FULMER (1), R. C. Kemerait (1), T. B. Brenneman (1)

(1) University of Georgia, Tifton, GA, U.S.A.

Phytopathology 104(Suppl. 3):S3.155

Haiti has been selected as part of the USAID Feed the Future program to reduce hunger, poverty and malnutrition in developing countries. Plumpy'nut, a peanut-based Ready-to-Use Therapeutic Food, has demonstrated significant 
effects in reversing malnourishment. Meds and Foods for Kids (MFK), a nonprofit organization, has begun making Plumpy'nut in Haiti. This has created a substantial demand for high quality, locally grown peanuts. However, all production is from smallholder farmers with very limited inputs. Yields are extremely low due to factors affecting soil fertility and defoliating fungi such as Puccinia arachidis and Cercosporidium personatum. Quality is also a problem and aflatoxin contamination from Aspergillus flavus is widespread. Growers generally lack the knowledge and resources needed to combat these issues. Since 2007, researchers from the University of Georgia, in collaboration with MFK, have been actively involved in Haiti. Multiple seminars have been held to equip local agronomists with the principles of peanut production and integrated disease management, and many field trials have been conducted. Results suggest that limited fungicide applications and improved varieties offer low-cost management strategies for improving yields. Recent funding from the USAID-supported Peanut and Mycotoxin Innovation Lab (Project UF-204) will allow for the continuance of extension and research efforts aimed at bettering the lives of those in Haiti.

\section{A window of opportunity: Summer tomato production in Bangladesh}

A. I. HUERTA (1), C. H. Lin (2), S. Ahmad (3), U. M. Zahir (4), M. N. Uddin (5), B. Sazib (6), J. F. Wang (2)

(1) University of Wisconsin, Madison, WI, U.S.A.; (2) AVRDC-The World Vegetable Center, Shanhua, Taiwan; (3) AVRDC-The World Vegetable Center, Dhaka, Bangladesh; (4) AVRDC-The World Vegetable Center, Jessore, Bangladesh; (5) Bangladesh Agricultural Research Institute, Gazipur, Bangladesh; (6) Bangabandhu Sheikh Mujibur Rahman Agricultural University, Gazipur, Bangladesh

Phytopathology 104(Suppl. 3):S3.156

Producing tomatoes during hot and wet seasons in the tropics is a challenge. However, the high price due to the low supply provides a good income opportunity for smallholders in developing countries. Use of rain shelter, fruit set hormone, and flood-tolerant and disease-resistant eggplant rootstock could increase tomato yield during the summer raining season. However, rain shelter and grafted seedlings require high economic inputs. We assessed the impact of rain shelter, grafting, or both technologies on tomato yield and potential profitability in Bangladesh. A split-plot design with grafting treatment as the main factor and rain shelter as the sub-factor was established in three research sites at Shanhua, Taiwan, and Gazipur and Jessore, Bangladesh from April to October 2013. All trials were managed according to local best agricultural practices and fruit-set hormone was applied to all plants. Data collected included all expenditures, incidence of prevalent diseases and insect pests, yield, and relevant environmental data. Tomato yellow leaf curl disease, black leaf mold, and bacterial spot were the predominant diseases observed, whereas tomato leaf miner and fruit borer were the most severe insect pests. Under the conditions tested, both grafting and rain shelter increased tomato yield at all locations. The results will provide information on how to apply these two treatments to maximize grower's profits.
Capacity building of tomato farmers in Ghana: The case of IPM package M. K. KWABENA OSEI (1), S. A. Miller (2), R. L. Gilbertson (3)

(1) CSIR-Crops Research Institute, Kumasi, Ghana; (2) Ohio State University, Ohio, OH, U.S.A.; (3) UC Davis, California, Davis, CA, U.S.A.

Phytopathology 104(Suppl. 3):S3.156

Tomato is sensitive to pest pressure and is therefore subjected to intensive application of synthetic pesticides some of which are toxic compounds. An integrated pest management (IPM) strategy through Farmer field Schools were put in place to teach farmers on how to minimize pest pressure, frequency and rate of pesticides application to protect both the environment and man in three regions of Ghana. Tomato varieties; Shasta, Heinz, OP-149, OP-155 and a local were used. Fields were designated as IPM and Farmer' beds to monitor differences in crop performance in the different farming systems. Tomato seedlings were planted in RCBD with five replications. Significant differences were observed among the varieties used across the Ashanti and Brong Ahafo regions in plant height, number of fruit per plant, fruit weight, number of plants infested with aphids and number of dropped fruits. There were however, no significant differences in fruit borers per plot, number of fruit dropped among the varieties in the Upper East region.

Seeding a participatory soil and plant health program in Morogoro, Tanzania

A. L. TESTEN (1), D. P. Mamiro (2), E. R. Mbega (3), S. A. Miller (1)

(1) The Ohio State University, Wooster, OH, U.S.A.; (2) Sokoine University of Agriculture, Morogoro, Tanzania; (3) Agricultural Research Institute Ilonga, Kilosa, Tanzania

Phytopathology 104(Suppl. 3):S3.156

Maximizing soil and plant health is essential for global food security, yet farmers in developing regions often lack resources to monitor crop and soil health. In the Morogoro Region of Tanzania, tomato production is constrained by poor soils, diseases, and lack of improved germplasm. Tomato is a major vegetable crop in Tanzania, providing income for farmers and nutrients for local consumers. To enhance regional tomato production, a participatory soil and plant health program is being developed. This program seeks to provide smallholder farmers with tools to monitor and manage the health of soils and crops. A portable soil test kit allows farmers to rapidly and inexpensively perform soil tests, such as $\mathrm{pH}$ and EC, allowing for better soil management decisions. Regional tomato disease surveys indicated that important dry season diseases are early blight, Septoria leaf spot, and root knot nematode, while common wet season diseases include bacterial wilt, late blight, and bacterial spot. From these findings, diagnostic guides were created for farmer and extension use. A soil bioassay is being developed to detect common soilborne diseases, and participatory variety selection trials are underway to identify locally acceptable disease resistant tomato varieties. Outcome mapping is being used to track project progress. Altogether, these efforts will lead to increased capacity for smallholder farmers to monitor and improve soil and tomato crop health in the Morogoro Region.

\section{Extension Yesterday, Today, and Tomorrow}

Future of extension: Challenges and opportunities

H. R. DILLARD (1)

(1) University of California, Davis, CA, U.S.A.

Phytopathology 104(Suppl. 3):S3.156

Cooperative Extension (CE) has a rich history of successful stakeholder engagement. Established 100 years ago, it enables a campus-to-community connection to better link land-grant universities to the public they serve. The system's strength is in delivering research evidence and science-based information to individuals, communities, businesses and stakeholders that assists in the development of practical solutions to real-world concerns. CE has been monetarily challenged over the years by the Great Depression, multiple recessions and reductions in government funding that have drastically reduced the workforce of extension specialists across the country. Furthermore, readily accessible information from the internet challenges the need for in-person expertise. Ironically, these challenges arise at a point in time of increasing critical societal needs and grand challenges, and increased demand for the expertise (knowledge and facilitation) of CE specialists. Although the challenges are significant, there are infinite opportunities for extension educators to inform important discussions and influence critical decisions. The future of extension may require educators to assume multiple roles, such as assembling and coordinating multidisciplinary teams of experts to address critical needs, collaborating and engaging with new and diverse audiences, finding new and multiple ways to communicate with stakeholders, and assuming strategic leadership roles.

\section{Challenges of funding an evolving extension service}

M. A. DRAPER (1)

(1) USDA-NIFA, Washington, DC, U.S.A.

Phytopathology 104(Suppl. 3):S3.156

In the world that we live in today, information sources are legion. We often hear of information overload. So much information is released and interpreted for the audience to address specific viewpoints. Discerning information has become a substantial challenge for our society today. Readers are challenged to determine validity and applicability. We are all tempted to prefer information that is consistent with some specific message. Our extension clientele face that challenge, as do our university administrations, our legislators, and even our scientists and extension specialists. Are we sufficiently analytical in today's culture? We may have ceded that responsibility to others. To confront the information quality challenge, Extension is faced with a greater need for communication than ever before. Compelling messaging must be nuanced for specific audiences. Legislators and government officials are more focused on oversight and accountability than ever before and they see competition as a surrogate for accountability. If science fails to recognize that Congress takes accountability and oversight seriously, that fatal step can endanger Extension's capacity funding. At this point Extension programs have the advantage and disadvantage of fewer 
reporting requirements than other federally funded programs at USDA-NIFA. Understanding reporting and non-traditional audiences will be critical to assuring a strong Cooperative Extension Service in the next 100 years.

\section{Extension today: Challenges of keeping extension relevant}

B. R. DURGAN (1)

(1) University of Minnesota, St. Paul, MN, U.S.A.

Phytopathology 104(Suppl. 3):S3.157

The Morrill Act of 1862 established land grant universities and the SmithLever Act of 1914 formalized Extension, mandating the Federal Government (through USDA) to provide each state with funds based on a populationrelated formula. Through these acts, the nation's more than 100 land grant colleges and universities "extend" their resources within their states and across the country, solving public needs with university resources through non-formal, non-credit programs. Throughout its history Extension in every state has connected the people with their land grant university. In the beginning, production agriculture was the primary focus of Extension. Extension programs quickly expanded to include youth development and home economics, however, the focus continued to be based on the issues of rural America. The programs of Extension today include many other areas and disciplines, including programs in both rural and urban areas. The future relevance of Extension will depend on Extension's ability to adapt and chance in response to societal needs, while remaining true to the land grant mission.

\section{History of extension and land-grant universities}

M. F. KHAN (1)

(1) North Dakota State University \& University of Minnesota, Fargo, ND, U.S.A.

Phytopathology 104(Suppl. 3):S3.157

The Morrill Land-Grant College Acts of 1862 and 1890 created the system of Land-Grant universities to provide higher education for the masses. The Hatch Act mandated the creation of agricultural experiment stations at Land-Grant Colleges and Universities. The Smith-Lever Act of 1914 established the Cooperative Extension Service to complement teaching and research at landgrant institutions. The role of Extension at its inception was to provide research based solutions to problems faced by farmers and the rural population, especially youths. Over the past century, the Cooperative
Extension Service has taken the University to the youths and adults in the US and has played an important role in improving our lives. The relevance of the Extension Services were highlighted during World Wars I and II and the Great Depression when it was in the forefront of increased food production, helped families adopt conservation programs to preserve their food so that it would be available for a longer period, and organized cooperatives and recruited volunteers to help producers. Extension has played a vital role in improving the health and nutrition of low-income families, and in providing a safe, reliable, abundant and relatively low cost food for all Americans. The success of the Cooperative Extension System is a result of its proactive and responsive roles in using relevant knowledge and technology to help youths and adults improve the quality of their lives.

\section{Education of future extensionists and clientele}

\section{S. A. MILLER (1)}

(1) The Ohio State University, Wooster, OH, U.S.A.

Phytopathology 104(Suppl. 3):S3.157

Farming has changed greatly in the 100 years since the beginning of Extension in the United States. In the past quarter century, the rate of change has greatly accelerated, with globalization driving farm consolidation and emphasis on production efficiency. At the same time, local food movements have renewed interest in farming on a small scale in peri-urban and urban environments. These shifts in production paradigms, along with global climate change, an apparent upswing in invasive plant pathogens and new emphasis on food safety have brought about new challenges in plant health management. Further, the communications technology revolution of the last 25 years has changed the way Extension clientele accept new information. Stakeholders now have access to large amounts of sometimes questionable information on the internet and other venues. The discipline of plant pathology must meet the challenge, in an era of reduced government support, to generate knowledge to solve plant health problems and convey that knowledge effectively to those who need it. To be successful, the next generation of Extension plant pathologists must be well-versed in modern technology for research and communication, and be able to adapt to changes that will continue to unfold at a rapid pace. Our students must also have a working knowledge of social science concepts to thrive in a participatory environment in which farmers and other stakeholders are active contributors.

\section{Funding Opportunities for Cooperative International Research}

Funding opportunities for agricultural research at USAID

J. E. BOWMAN (1)

(1) USAID, Washington, DC, U.S.A

Phytopathology 104(Suppl. 3):S3.157

Most funding opportunities for agricultural research at USAID emanate from the Office of Agricultural Research (ARP) and Policy, which is part of the Bureau for Food Security (BFS). The current portfoilio of agricultural research projects at BFS/ARP will be briefly described, with a focus on the predominant mechanisms and procedures for applicants to win new research grants and/or participate in existing grants. Most of the existing research opportunities are related to the "Feed the Future" Program, a Presidential Initiative implemented by USAID and other U.S. government agencies.

\section{International programs and opportunities at NIFA}

K. F. CARDWELL (1)

(1) USDA, National Institute of Food and Agriculture, Washington, DC, U.S.A.

Phytopathology 104(Suppl. 3):S3.157

The USDA mission plan has specific goals to collaborate on national and international levels to ensure our research, education, and extension activities are representative of current priorities and take advantage of existing knowledge. The NIFA vision and strategic plan see the agency as having successful partnerships across the nation and around the world. Applicants to Foundational or Challenge Area RFAs may include international partnerships or engagement in proposals. Applicants are asked to keep in mind that while international activities may contribute to global food security, as described in the U.S. Government's Feed the Future initiative and to solutions to natural resource and sustainability issues, any international activity proposed under AFRI such as partnerships, exchanges, training, travel, etc., must primarily support NIFA's domestic program goals. Applicants must describe how international activities proposed in applications will contribute to and support advances in American agriculture. If international activities are proposed, applicants must describe appropriate indicators such as those posted at the global food security initiative Web site (www.feedthefuture.gov/progress). Additional guidance and suggested examples for possible international partnerships linked to an AFRI RFA are provided in the AFRI Water for Agriculture Challenge Area Frequently Asked Questions (FAQs) (http://www.nifa.usda.gov/funding/afri/afri_faq_webinars.html).

\section{USAID fellowship programs}

C. K. COHEN (1)

(1) US Agency for International Development, Washington, DC, U.S.A. Phytopathology 104(Suppl. 3):S3.157

How can plant pathologists contribute to addressing global agricultural development challenges and building scientific and technical capacity in the developing world? This presentation will discuss needed skills sets and opportunities for students, faculty, and administrators to get involved, with a particular focus on the US Agency for International Development's Feed the Future programs.

The Borlaug Global Rust Initiative: A successful cooperative international research community

M. ROUSE (1), S. D. Evanega (2), R. Coffman (2)

(1) USDA-ARS and University of Minnesota, St. Paul, MN, U.S.A.; (2) Cornell University, Highland, NY, U.S.A.

Phytopathology 104(Suppl. 3):S3.157

The Borlaug Global Rust Initiative (BGRI) was launched by wheat scientists in 2005 to raise awareness and address the threat of Ug99 stem rust. In 2008, the Bill and Melinda Gates Foundation funded the Durable Rust Resistance in Wheat (DRRW) project with an initial investment of \$26 million USD followed by $\$ 40$ million USD in 2011 in cooperation with the UK Department for International Development. The DRRW project involves over 22 partners from around the world forming a multifaceted approach to protect wheat from Ug99 stem rust. Since 2008, scientists involved in the project have made significant advances including the increase or release of $39 \mathrm{Ug} 99$-resistant wheat varieties in nine countries in Asia and East Africa where Ug99 poses 
the greatest threat. BGRI/DRRW scientists have described molecular markers linked to 15 known $\mathrm{Ug} 99$ resistance genes and have described 25 previously uncharacterized Ug99 resistance loci. This diversity of genetic resources provides wheat breeders with the tools necessary to incorporate multiple Ug99 resistance genes in cultivars. Comprehensive investments in rust research capacity in East Africa, pathogen monitoring through surveying rust incidence, race-typing international stem rust collections, developing dispersion models, surveying the alternate host of the stem rust pathogen, and utilization of molecular assays for detection of Ug99 have provided timely data on the status of Ug99 and facilitated effective resistance breeding.

\section{Plant Pathologists of the Future: Showcasing the Top Graduate Students from APS Division Meetings}

North Central Division - Frankliniella occidentalis proteins that interact or respond to Tomato spotted wilt virus infection of the insect vector I. E. BADILLO-VARGAS (1), D. Rotenberg (1), A. E. Whitfield (1) (1) Department of Plant Pathology, Kansas State University, Manhattan, KS, U.S.A.

Phytopathology 104(Suppl. 3):S3.158

Tomato spotted wilt virus (TSWV) is one of the ten most devastating plant viruses. It is transmitted by the western flower thrips, Frankliniella occidentalis, in a persistent propagative fashion. TSWV binds to and enters the thrips midgut, replicates in the midgut and surrounding muscle tissue, then journeys to and replicates in salivary gland tissues for transmission to occur. The goal of this work was to identify thrips proteins that directly interact with TSWV and those that respond to virus infection. Using two-dimensional (2-D) gel electrophoresis, we identified 26 protein spots that displayed differential abundances in response to TSWV infection. Mass spectrometry and Mascot searches resulted in the identification of 37 thrips proteins within the 26 spots. Thirty two of these proteins had gene ontologies representing biological roles of proteins associated with infection cycles of other plant- and animalinfecting viruses and antiviral defense responses. Overlay assays were performed using 2-D gels to identify larval thrips proteins that directly interact with TSWV virions or a TSWV glycoprotein $\left(\mathrm{G}_{\mathrm{N}}\right)$ shown previously to play a role in viral attachment to thrips guts. Four proteins interacted with purified TSWV virions, one of which also interacted with recombinant $\mathrm{G}_{\mathrm{N}}$. Identification of thrips molecules putatively involved in the infection of the insect vector provides new insights into the molecular basis of this interaction and novel targets for control.

Northeastern Division - A proposed new model for beech bark disease development in aftermath forests

J. A. CALE (1), S. A. Teale (1), M. T. Johnston (2), J. D. Castello (1)

(1) SUNY ESF, Syracuse, NY, U.S.A.; (2) SUNY ESF, Ranger School, Wanakena, NY, U.S.A.

Phytopathology 104(Suppl. 3):S3.158

Neonectria ditissima and $\mathrm{N}$. faginata are causal agents of beech bark disease (BBD) in North America. Infection of American beech (Fagus grandifolia) by these fungi is believed to follow a single predisposing factor, infestation by beech scale (Cryptococcus fagisuga). Recent work suggests the influence of alternative or additional predisposing factors. A more complete understanding of the pathosystems of each BBD pathogen is integral to developing effective management strategies for BBD aftermath (long-affected) forests. Although several physiological and nutritional factors differ between healthy, infested, and infected beech, the possible role of these factors in predisposing infection has not been examined. We conducted a case-control study investigating potential entomological, nutritional, and physiological factors predisposing beech to infection by Neonectria pathogens, separately and together. Infection by $\mathrm{N}$. ditissima in 2012 was positively related to Xylococculus betulae densities and isohamnetin concentration in 2011. Infection by N. faginata in 2012 was positively related to beech scale densities and catechin concentration in 2011. Low bark phosphorus in 2011 was a predisposing factor important to the pathosystems of both fungi. These findings considerably expand the long-standing model of BBD development for aftermath forests and have important implications for managing BBD-affected forests.

\section{Southern Division - Effects of infection timing on Wheat streak severity} J. A. PRICE (1), J. Gray (2), F. Workneh (2), C. M. Rush (2)

(1) Texas A\&M AgriLife Research, Amarillo, TX, U.S.A.; (2) Texas A\&M AgriLife Research, Bushland, TX, U.S.A.

Phytopathology 104(Suppl. 3):S3.158

Wheat streak mosaic virus, vectored by the wheat curl mite (Aceria tosichella Keifer), causes severe reductions to grain production and water use efficiency and is one of the most economically important wheat viruses found throughout the Great Plains region of the United States. Dual purpose wheat, for grazing and grain production, is typically planted late August to early
September when average temperatures are warm, increasing the likelihood of early virus infection. Delaying planting until cooler temperatures usually results in reduced disease incidence and severity, possibly due to environmental conditions not optimal for both vector and virus. Little is known about the impact of early and late spring infections on disease severity, yield, and water use efficiency. Therefore, studies were conducted to evaluate the effects of early, middle, and late spring virus infections, at three different irrigation levels. Significant increases in disease severity, soil moisture, and decreased grain yield were found for fall inoculated plots. Later season inoculations were found to have increased grain yield, water use efficiency and decreased severity. However, uniform reductions in disease severity were not found during the early and mid-spring treatments, which were influenced by cooler temperatures at the time of inoculation. This information can be used to design precision management strategies during Wheat streak infection and for modeling disease loss estimates.

Pacific Division - What Alternaria species cause diseases of potato in the Pacific Northwest?

L. TYMON (1), T. F. Cummings (1), T. L. Peever (1), D. A. Johnson (1)

(1) Washington State University, Pullman, WA, U.S.A.

Phytopathology 104(Suppl. 3):S3.158

Isolations from early blight and brown spot lesions on potato leaves collected in the Pacific Northwest were made between 2008 and 2011 to study the diversity of fungi causing these diseases. Large-spored isolates from Section Porri $(A s)$ were isolated less frequently ( $42 \%$ overall) than small-spored isolates in Section Alternaria $(A a)(50 \%$ overall) in all years except 2010. Pathogenicity was assessed on detached leaves of 'Russet Norkotah'. Seventythree $\%$ of $A a$ isolates and $92 \%$ of $A s$ isolates were pathogenic, respectively. A restriction digest of SCAR marker OPA1-3 was used to distinguish phylogenetic species within the section alternata. Twenty-three of 66 isolates were identified as $A a$ and 36 isolates as $A$. arborescens. No correlation was observed between pathogenicity and phylogenetic species $(\mathrm{r}=0.12, P=0.33)$ Seven isolates had no restriction site and were identified as phylogenetic species $A$. oregonensis, $A$. arbusti, or A. metachromatica in section infectoria by sequencing of g3pd. Aggressiveness of $A s, A a$, and $A$. arbusti to potato was quantified on non-wounded and wounded detached leaves. Mean infection frequencies (MIF) and area under the lesion expansion curve (AULEC) were significantly greater for $A s$ than for $A a$ or $A$. arbusti on non-wounded leaves and wounding of tissue significantly increased MIF and AULEC of $A a$ but only MIF significantly increased for $A$. arbusti relative to non-wounded tissue.

Potomac Division - Xanthomonas effector AvrRxo1 suppresses plant immunity by regulating the plant stomatal aperture sizes

S. WU (1), C. Zhou (1), Y. Liu (1), Q. Cheng (2), B. Zhao (1)

(1) Virginia Tech, Blacksburg, VA, U.S.A.; (2) Nanjing Forestry University, Nanjing, China

Phytopathology 104(Suppl. 3):S3.158

Rice bacterial leaf streak disease caused by Xanthomonas oryzae pv. oryzicola $(X o c)$ is one of the most important bacterial diseases in rice fields. A type III effector gene avrRxol was isolated from the genome of Xoc. Ectopic expression of avrRxol in Arabidopsis could suppress plant immunity in Arabidopsis. In aim to identify the virulent targets of AvrRxo1, we screened two Arabidopsis yeast two-hybrid cDNA libraries by using AvrRox1 as the bait. As a result, AIN2 was identified as a putative transcription factor that has two homologues in the Arabidopsis genome. And AvrRxo1's virulence function was compromised on the mutant of ain2. To identify Arabidopsis genes regulated by AvrRxo1 and AIN2, we performed RNA-seq analysis on the AvrRxo1 transgenic and ain2 mutant Arabidopsis plant, which allows us to identify a collection of AvrRxo1 induced genes (AIG). We further demonstrated that AvrRxo1 stabilized Ain2, in order to induce the expression of its direct target gene aigl. Overexpression of aigl in Arabidopsis inhibited stomata closing, and suppressed plant immunity. Our result illustrated AvrRxo1 manipulated Ain2 to compromise Arabidopsis defense system, which suggested Ain2 plays an important role in plant immunity. Further characterization of Ain2 in Arabidopsis may help us gain new insight of plant immunity and develop new strategy to achieve durable disease resistance in crop plants. 


\section{What's App? Using Apps and Technology in Integrated Plant Disease Management Programming}

Plant pathology for a song: App use in the classroom (and hitting the right notes)

J. BECKERMAN (1), C. Sadof (1)

(1) Purdue University, West Lafayette, IN, U.S.A.

Phytopathology 104(Suppl. 3):S3.159

We recently integrated the Purdue Plant Doctor series of smartphone apps, originally designed for extension audiences, into an undergraduate pest management course. Students worked in small teams and used the apps to address plant health problems in the field, often under competitive situations. We were successful by making the interaction between the student, the app and our class interactive, and used pop culture to drive the experience and promote problem-based learning. Student learning changed from finding (or memorizing) information into using information to solve problems. This approach also helped students develop important diagnostic and critical thinking skills, while promoting collaboration. We found that incorporating apps into our class has not only changed our teaching, but student learning and course outcomes for the better, and provided a new way to deliver relevant information quickly and efficiently. Our new goal became to engage students without letting the technology get in the way. The promise of using apps isn't about the apps (or the operating system, learning management systems, or software code): It's about the opportunity to develop new ways to promote and improve learning. However, in developing any new technology, we must ask ourselves: What do we want students to learn? What resources do we have available? What are our measures of success? And, perhaps the most limiting: What is our own sense of possibility?

Integrating grower-driven and publically held data for improved plant protection

R. GROVES (1), K. Frost (1), A. Huseth (2)

(1) University of Wisconsin, Madison, WI, U.S.A.; (2) Cornell University, Ithaca, NY, U.S.A.

Phytopathology 104(Suppl. 3):S3.159

The seed potato industry has identified Potato virus Y (PVY) as its most serious disease problem. Publically held, regional and national databases have recently become available to provide information about which aphid species are moving into susceptible seed potato, when the flights occur, and the composition of adjoining landscapes. The overall goal of this research has been to determine the seasonal phenology of dispersing aphid vectors and describe how local landscape composition influences the abundance and species composition of aphids associated with PVY spread. Data have recently been compiled from the NCR Aphid Suction Trap Network from over a span of 8 years (2005-2013) and 45 locations comprising over 200 species of aphids. Suction trap information has been standardized for each year, location, and week using a random effects model. Tabulated Cropland Data Layer pixels within field management units will be estimated from the majority pixel type and classified by crop identity. Average distance estimates can then be analyzed used as regressors to determine which crop types correlate with PVY incidence. The expected outcomes are to develop aphid phenology models to accurately determine periods of elevated risk for transmission of PVY, and spatially-explicit tools to describe the influence of local and regional landscape structure on risk for transmission of PVY into susceptible seed potato crops.

Gene-Z and iDx: Affordable hand-held decentralized genetic testing platforms

S. HASHSHAM (1), R. Stedtfeld (1), M. Kronlein (1), E. Gulari (2), J. Tiedje (1)

(1) Michigan State University, East Lansing, MI, U.S.A.; (2) University of Michigan, Ann Arbor, MI, U.S.A.

Phytopathology 104(Suppl. 3):S3.159
Decentralized analysis of nucleic acids-based markers is critical in many areas including screening of disease and pathogens, surveillance, and risk assessment. Networkable, simple, and low cost hand-held genetic analysis devices have the added benefit of pooling field data and predict spread of disease based on weather patterns. This presentation will introduce two networkable platforms (named Gene- $Z$ and $i D x$ ) developed in our lab to provide simplified analysis of genetic markers. Gene-Z is Android/iPod based and capable of carrying out quantitative isothermal amplification for 64 reactions in a disposable microfluidic chip. The device is battery operated and can be charged by solar panels integrated at the top of the device. A smaller version (iDx) working as an attachment to cell phones, also with real time amplification and quantification capabilities, allows 8 reactions in parallel. Both these devices are networkable and currently being validated for a number of key applications important to human and animal health, plant safety, industrial microbiology, and environmental protection. Simplification, reliability, and cost-effectiveness are key factors ensuring successful implementation of such approaches. Combined with a sustainable business model, such devices are expected to provide analysis of genetic markers in a simple, affordable, field deployable, rapid, multiplexed, and robust manner without the need for electrical power or refrigerated reagents.

The Turfpath App: Crowdsourcing the path of turfgrass pests J. E. KAMINSKI (1)

(1) Penn State, University Park, PA, U.S.A.

Phytopathology 104(Suppl. 3):S3.159

Crowdsourcing data can be an effective way to track information. The increased use of smartphones and various social media platforms make hating information fast and easy. Turfpath is a mobile application designed to track the spread and activity if pests in the Turfgrass industry. Combined with social media platforms like Twitter and Facebook, Turfpath gathers pest updates from turfgrass experts and novices. Users can also share unidentified issues in an effort to solve their pest challenges and provide GPS tracking of active disease, weed and insect pests. Launched in April 2013, Turfpath has over 11,000 downloads and nearly 2 million page views within the app. This seminar will highlight the function of GPS, crowdsourced mobile applications and one of the challenges of their development.

\section{Are apps the future?}

D. MUELLER (1), B. Anderson (2)

(1) Iowa State University, Ames, IA, U.S.A.; (2) Vox Media, Ames, IA, U.S.A.

Phytopathology 104(Suppl. 3):S3.159

There was a paradigm shift in the print world when the web first came about. At first, existing publications were simply repurposed for the web. They did not take advantage of the new medium's capabilities; they were just doing the same thing in a new space. It took years for people to see the web as a system allowing for far more dynamic interactions, like community formation around niche topics. Mobile apps and hand held devices take the communities and interactions of the web-era to a new and deeper level using precise location data, push notifications, and other capabilities. Yet we can also fall into the trap of repackaging the old. If we see websites as a new way to print static journal articles or if eBooks are just a cute way to get dynamic fonts and lighter loads for students - we missed it. If apps are a new way to blend content, images, video, and calculators - we again missed it. If apps are the next steps in strengthening communities and improving interactions, investing in talent and infrastructure to support and capitalize on these opportunities is necessary. We need to understand how to use apps to share data and interact with the people we serve. A vision and willingness to hire the right people will be required to create a system that powers many apps, websites, and research engines. Poorly done, we will have one-use siloes that wither and die. Our infrastructural decisions today will impact our ability to fully utilize these tools in the future. 